

\section{DISCLAIMER}

This report was prepared as an account of work sponsored by an agency of the United States Government. Neither the United States Government nor any agency Thereof, nor any of their employees, makes any warranty, express or implied, or assumes any legal liability or responsibility for the accuracy, completeness, or usefulness of any information, apparatus, product, or process disclosed, or represents that its use would not infringe privately owned rights. Reference herein to any specific commercial product, process, or service by trade name, trademark, manufacturer, or otherwise does not necessarily constitute or imply its endorsement, recommendation, or favoring by the United States Government or any agency thereof. The views and opinions of authors expressed herein do not necessarily state or reflect those of the United States Government or any agency thereof. 


\section{DISCLAIMER}

Portions of this document may be illegible in electronic image products. Images are produced from the best available original document. 
LBL-10166

$\mathrm{CP}-12$

\title{
CHEMISTRY OF SILICA IN CERRO PRIETO BRINES
}

\author{
by
}

\author{
Oleh Weres \\ Leon Tsao \\ Eduardo Iglesias
}

Apr11 1980

\author{
Earth Sclences Division \\ Lawrence Berkeley Laboratory \\ University of California \\ Berkeley, California 94720
}

\section{Prepared for the U.S. Department of Energy under \\ Contract W-7405-ENG-48}

DISCLAMEER

This book was prepered as an sccount of work soonsored by an wency of the United States Government. Neither the United States Government nor any agency therroof, nor my of their employees, makes smy

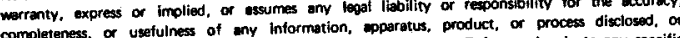
represents that its use would nor infringe privately oumbd rights. Reference herein to my pecific commerciat product, process, or service by trade name, trademerk, monulacturer, a otherwise, does not nocessarily constitute or imply its endorsement, recommendation, or fworing oy the Unh States Govermment of any agency thereot. The views and opinions of wuthors expressed herein do not 



\section{Table of Contents}

List of Tables

List of Figures

$\underline{\text { Page }}$

iii

iv

Abstract

si - Introduction

S2 - Real Brines and Synthetic Brines

s3 - Silica Removal Studies: Experim

S4 - Silica Removal by Increasing $\mathrm{pH}$

S5 - Effect of SynthetIc Flocculants and Summary $\quad 15$

S6 - Field Verification of Laboratory Results $\quad 21$

57 - Recommendation for a Pilot Plant Test $\quad 24$

S8 - Scale Deposition from Synthetic Brines: Experimental Methods 28

S9. - Scale Deposition: Experimental Results $\quad 35$

S10 - The Morphology of Silica Scale

si1 - The Equilibrium Chemistry of Cerro Prieto Brines $\quad 43$

S12 - Conclusions

Acknowledgements

Appendix 1 - Continuous Silica Recharge Experiment

55

Appendix 2 - Precipitation of Calclum Carbonate from Synthetic Brine

\section{List of Tables}

Table 1 - Compositions of Natural and Synthetic Cerro Prieto Brines

Table 2 - Results of Flocculation Experiments with High Ca Synthetic Brine

Table 3 - Results of Flocculation Experiments with Low Ca Synthetic Brine

Table 4 - Synthetic Flocculants Tested

Table 5 - Solutions Used in Synthetic Scale Deposition Experiments 
L1st of Flgures

Page

Fig. 1 - Suspended Silla vs. pH. 11

Fig. 2 - Effect of Increasing the $\mathrm{pH}$ of a High Ca Synthetic Brine 12

Fig. 3 - Effect of Increasing the pH of a Low Ca Synthetic Brine 15

Fig. 4 - Effect of Adding Magnifloc 573C to a High Ca Synthetic Brine

Fig. 5 - Unmodified Brine from Cerro Prieto Well M-30 22

Fig. 6 - Effect of Adding Lime to Brine from $M-30 \quad 22$

Fig. 7 - Effect of Adding Lime to Brine from $M-14 \quad 23$

Fig. 8 - Effect of Adding Magnifloc $\$$ 573C to Brine from $M-14 \quad 23$

Fig. 9 - Schematic of Recommended Pliot Plant 25

F1g. 10 - Schematic of Synthet1c Scale Deposition Apparatus 29

F1g. 11 - Photographs of Synthetic Scale Deposition Apparatus 30

Fig - 12 - Scaling Rate v8. Position and TIme 36

F1g.13 - Effect of $\mathrm{pH}$ on Scaling Rate 37

F1g- 14 - Silica Deposits from Low Pressure Steam Separators 39

F1g. 15 - "Vitrified Scale" from a Low Pressure Steam Separator's Brine Discharge Line

Fig. 16 - "Synthetic" Silica Scale $\quad \cdots \quad 42$

F1g. 17 - Effects of Adjusting pH on Saturation Ratios of Carbonate and Sulfate Minerals

Fig. 18 - Schematic of Acld Injection for Elimination of Bicarbonate

F1g. 19 - Partition between Carbon Dioxide and Bicarbonate as a Function of $\mathrm{pH}$

Fig. 20 - Effect of Adding Sulfuric Acid on Saturation Ratios of Sulfate Minerals

Fig. 21 - Effect of then Adding Lime on the Saturation Ratios of Carbonate Minerals

Fig. Al - Total and Molybdate Active Silica vs. Time In a Continuous Recharge Experiment

Fig. A2 - Specific Deposition Rate and Its Reciprocal vs. Time In a Continuous Recharge Experiment 


\section{Abstract}

The precipitation of amorphous silica from synthetic geothermal brines which resemble the flashed brine at Cerro Prieto has been studied. It was found that part of the dissolved silica quickly polymerizes to form suspended colloidal silica. The colloldal silica flocculates and settles slowly at unmodifled brine $\mathrm{pH}$ values near 7.35. Raising the $\mathrm{pH}$ of the brine to about 7.8 by adding base and stirring for a few minutes causes rapid and complete flocculation and settling. These results have been confirmed in the field using actual Cerro Prieto brine. Both in the laboratory and in the field quaternary amines were found to be effective with some brine compositions but not with others. Polyacrylamides do not work at all.

These results suggest the following simple preinjection brine treatment process: age the brine for 10-20 minutes in a covered holding tank, add 20-30 ppm lime ( $\mathrm{CaO})$, stir for 5 minutes, and separate the flocculated silica from the brine using a conventional clarifier. The brine coming out of such a process will be almost completely free of suspended solids.

The pilot plant tests needed to reduce this conceptual process to practice are discussed.

The rate of deposition of silica scale from synthetic brines was separately studied. It was found that a modest decrease in $\mathrm{pH}$ could significantly reduce the scaling rate at a reasonable cost.

The equilibrium chemistry of Cerro Prieto brine was studied theoretically. These calculations indicate that increasing the brine $\mathrm{pH}$ to remove silica might cause some precipitation of carbonate minerals, but also that this problem could easily be eliminated at a reasonable cost if it did arise. 
The work reported here was conducted in support of the ongoing studies on brine relnjection at Cerro Prieto being conducted by the personnel of the Comision Federal de Electricidad (CFE) and the Instituto Investigaciones Electricas (IIE). It was part of the research project at the Lawrence Berkeley Laboratory (LBL) which is part of the CFE-DOE Cooperative Program at Cerro Prieto.

For the purposes of this study, it was assumed that the brine to be reinjected will be flashed and separated from steam twice, and that it will be delivered to the brine treatment facility at atmospheric pressure and a temperature near $100^{\circ} \mathrm{C}$. These assumptions are consistent with CFE's long term field development plan. Under these conditions cerro Prieto brine is supersaturated relative to amorphous silica by about threefold, and the excess silica in solution is rapidly converted to suspended colloidal silica by homogeneous nucleation and growth of colloldal particles. The flocculation of this colloldal sillca and its adhesion to solld surfaces creates the massive white amorphous sillca deposits which form throughout the existing surface brine disposal system at Cerro Prieto.

Injecting brine which contains $400-500 \mathrm{mg} \mathrm{L}^{-1}$ suspended solids into a reservoir having pore-dominated permeability, 1ike that at Cerro Prieto, w11l cause severe formation damage. Therefore, this colloidal silica must somehow be removed prior to reinjection.

The major task assigned to us was to research methods to remove silica from flashed brine to make it fit for reinjection. A secondary task was to study the rate of silica scale deposition from flashed brine at about $100^{\circ} \mathrm{C}$ and means of controlling 1 t.

Most of our work was experimental, and was performed in our laboratory using synthetic brines. Some fleld work was performed also at Cerro Prieto to verify the results obtained in our laboratory. The experimental techniques employed by us in this work are based on and are an extension of the techniques developed during an earlier study of the chemical kinetics of silica polymerization in geothermal brine-1ike solutions (Weres et al., 1980).

The staff of the IIE and CFE laboratories at Cerro Prieto have recently performed similar experiments and confirmed our results (Hurtado, et al., 1979). 
They are presently testing the brine treatment process recommended to them by us (see Section 7) on a pllot plant scale, and the results of this work should be avallable shortly.

The carbonates and sulfates of calclum, strontium, and barium are the materials other than sillca most likely to precipitate and cause formation damage after reinjection. This possiblity was studied theoretically.

Additional experimental techniques that were developed but not perfected as well as preliminary data generated by them are presented and discussed in the Appendices.

Much of the material in this report is contained in two papers that were presented by 0 . Weres and L. Tsao, and E. Iglesias and 0 . Weres, respectively, at the Second Symposium on the Cerro Prieto Geothermal Field that was held in Mexical1, October 17-19, 1979. These papers will be published as part of the Proceedings of this Symposium and will also be submitted for publicaton in Geothermics.

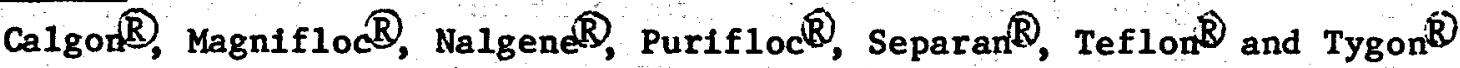
are all registered trademarks although they are not always identified as being such in the text and figures.

\section{Real Brines and Synthetic Brines}

The precipitation of amorphous sllica from Cerro Prieto brines was studied by preparing synthetic brines that closely resemble them in our laboratory. The approximate chemical compositions of two such synthetic brines which were extensively used in the silica removal studies are presented in Table 1. The silica concentrations and $\mathrm{pH}$ values shown in the Table were those we used most often. However, some work was also done at different silica concentrations and pH's. The concentrations of all other components were always approximately as shown in the Table. (The concentration of sodium varied slightly with the silica concentration and $\mathrm{pH}$. Also, evaporation tended to concentrate the brines slightly during the experiments.)

These synthetic brines were formulated to have concentrations of their major components in the same range as real Cerro Prieto brines that have been flashed down to atmospheric pressure. The "High $\mathrm{Ca}$ " formulation was more-orless arbitrarily chosen to resemble a "typical" flashed brine at Cerro Prieto. 
TABLE 1. Natural and Synthetic Cerro Prieto Brines

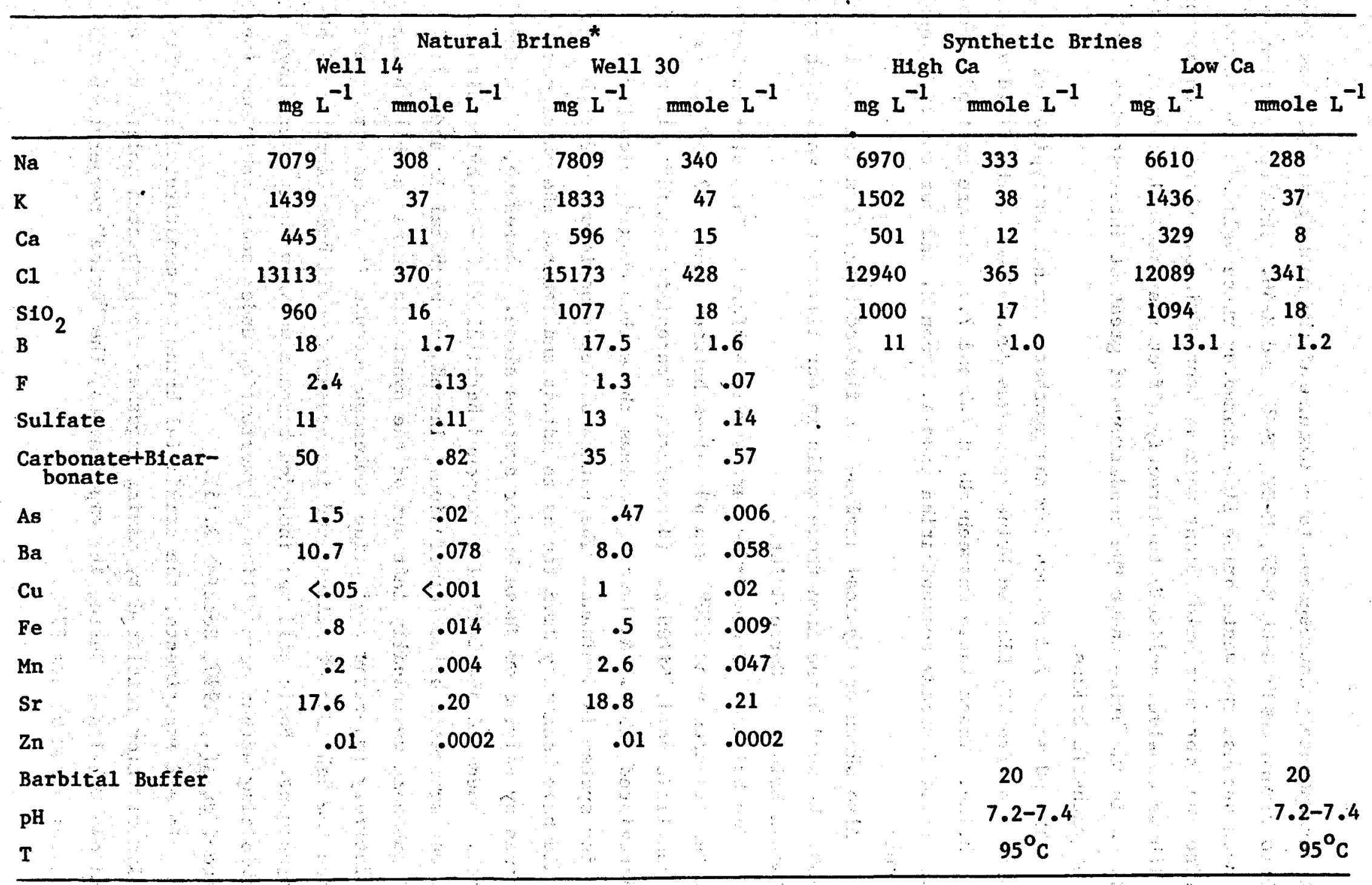

*Values quoted and recalculated from Cosner and Apps (1978), Records 68 and 106. This data was generated by the CFE Laboratory at Cerro Prieto and kindly provided to LBL by A. Mañon M. 
It approximately corresponds to a mixture of the waste brine streams from Cerro Prieto wells $M-8, M-27, M-31, M-35$, and $M-46$. This composition was chosen because the waste brine line shared by these wells is the source of brine used for most pilot plant work at Cerro Prieto. Chemical components which we consider unlikely to directly affect the chemical behavior of the the silica in the brine under the conditions of greatest interest were left out of our synthetic brines.

The $\mathrm{pH}$ value 7.3 chosen for the synthetic brines is typical of the $\mathrm{pH}$ values of freshly flashed brine specimens determined in the field with stillhot brine. These range between about 7.0 and 7.6 , and are most of ten about 7.3 or 7.4 (private communication from A. Mañon M. and our own field measurements).

Also shown are typical analyses of flashed brine from wells M-14 and M-30. We used brine from these wells in our limited field work with freshly flashed brines at Cerro Prieto.

The brines at Cerro Prieto are weakly buffered. The major buffer at temperatures near $100^{\circ} \mathrm{C}$ and $\mathrm{pH}$ values between about 7.2 and 9.5 is monosilicic acid, $\mathrm{S} 1(\mathrm{OH})_{4}$. (Henceforth, "monosilicic acid" will be abbreviated "MSA".) At lower $\mathrm{pH}$ values the carbon dloxide bicarbonate buffer system is dominant. The nature of our experiments was such that it would have been very hard for us to adjust and control the $\mathrm{pH}$ of our synthetic brines by relying on these buffer systems alone. Therefore, we Included a small amount of the buffering compound barbital $\left(5,5^{\circ}\right.$-diethylbarbituric acid) in our synthetic brine formulation. The $\mathrm{pR}_{a}$ of barbital is about 7.4 . Bicarbonate was usually left out of the synthetic brines despite being a relatively important real brine component because it has no direct effect upon the behavior of silica, and its presence would have complicated $\mathrm{pH}$ adjustment. Boric acid was included because we know that it can have a mild inhibiting effect upon silica polymerization under some conditions (see Weres, et al., 1980, Section 3.15).

In all experiments, the artificial brine was constituted and silica polymerization initiated by mixing together two preheated solutions, one acid and one alkaline. During the experiments, the "brine" temperature was always betweęn about 92 and $97^{\circ} \mathrm{C}$. 
In these experiments the alkaline solution consisted of a premeasured amount of dilute sodium metasilicate solution. The acid solution contained the appropriate amounts of the maj or component salts, sodium barbital, acid to adjust the buffer $\mathrm{pH}$ and neutralize the silica, and water to make up the total desired volume. A total volume of $0.3 \mathrm{~L}$ was usually employed.

Throughout our work with simulated brines, all volumes were measured at room temperature. Therefore, when we say $0.3 \mathrm{~L}$, we mean that the volume would be that if the solution were cooled down to room temperature. When applied to salt concentrations and Initlal slifca concentrations, units of moles or grams per liter are also used in this sense. Because of the relatively low sait content of these solutions and the semiquantitative nature of most of the synthet1c brine data, this 1s, for all practical purposes, the same as moles or grams per $\mathrm{kg}$ of water.

The sodium metasilicate stock solution contalned about $2 \mathrm{~g} \mathrm{~L}^{-1} \mathrm{SiO}_{2}$. Because it was hard to make up this solution to an exact predetermined concentration, it was always standardized by comparison with a standard silica solution (Fischer AA standard).

The desired amount of sodium metasillcate solution was put into a plastic bottle, some of the remalning air squeezed out, and the cap closed tightly. It was then put into a boiling water bath to preheat. (This procedure ensured that the bottle would nelther rupture nor lose water when heated.) A separate 50-ml aliquot of the sodium metasilicate solution was titrated with $0.5 \mathrm{M} \mathrm{HCl}$ using a pH meter to determine the volume of HCl solution needed to neutralize the given amount of sodium metasilicate solution.

The acid starting solution was prepared from a stock solution of "concentrated brine", a stock solution of sodium barbital, $0.5 \mathrm{M} \mathrm{HCl}$, and water. The "concentrated brine" was a mixture of sodium, potassium and calctum chlorides and boric acid in water formulated so that putting 3 parts of 1 in into 20 parts of the final synthetic brine would give the desired final major component concentrations. For example, In the case of the "High Ca" synthet Ic brine presented $1 \mathrm{n}$ Table 1 , the "concentrated brine" contained $1.667 \mathrm{M} \mathrm{NaCl}$, $0.256 \mathrm{M} \mathrm{KCl}, 0.0833 \mathrm{M} \mathrm{CaCl}_{2}$ and $0.0066 \mathrm{M} \mathrm{B}_{3} \mathrm{BO}_{3}$. The concentrations of the last three components in this concentrate are simply $20 / 3$ times their 
desired concentrations in the synthetic brine. The concentration of $\mathrm{NaCl}$ is somewhat smaller because the sodium metasilicate and buffer stock solutions also contain sodium.

In the case of the "Low $\mathrm{Ca}$ " synthetic brine, the "concentrated brine" contained $1.547 \mathrm{M} \mathrm{NaCl}, 0.245 \mathrm{M} \mathrm{KCl}, 0.0547 \mathrm{M} \mathrm{CaCl}_{2}$, and $0.0081 \mathrm{M} \mathrm{H}_{3} \mathrm{BO}_{3}$.

The barbital buffer stock solution was prepared to be $0.5 \mathrm{M}$ in barbital and $0.5 \mathrm{M}$ in NaOH. "Purified" grade Mallinckrodt barbital intended for pharmaceutical use was employed. (All chemicals used other than the barbital and the commercial flocculants were of reagent grade.)

To prepare the acid solution, measured amounts of the brine concentrate, buffer stock solution, and the amount of water needed to bring the final volume up to that desired were mixed in a beaker suspended in a boiling water bath. The beaker was temporarily covered with a watchglass and its contents allowed to heat up to above about $90^{\circ} \mathrm{c}$. Next, the mixture was titrated with $0.5 \mathrm{M} \mathrm{HCl}$ to adjust the $\mathrm{pH}$ value to that desired in the synthetic brine. Finally, the amount of additional $0.5 \mathrm{M} \mathrm{HCl}$ needed to neutralize the sodium metasilicate solution, as determined by the earlier titration, was added to the beaker, and the resulting mixture was again allowed to heat up.

To start the reaction, the preheated alkaline solution was poured into the beaker containing the preheated acid solution with rapid stirring. The stirring was stopped after a few seconds, the $\mathrm{pH}$ measured, and periodic $1 \mathrm{~m} 1$ samples withdrawn for analysis from then on.

Both dissolved silica and total silica were determined for by the molybdate yellow method. To determine the molybdate active (i.e., "dissolved") silica, the molybdate yellow method was employed directly. To determine the total silica (i.e., including the suspended colloidal silica), the specimen was first reacted with $\mathrm{NaOH}$ to digest and dissolve the colloidal silica. (Henceforth, "molybdate active silica" will be abbreviated as "MAS", which should not be confused with "MSA". MSA is molybdate active but so are some other small molecular and lonic silica species.).

The difference between the empirically determined molybdate active and total silica concentrations is approximately equal to the amount of colloidal silica suspended in the "brine". This "differential" technique is sensitive dorn to about $10 \mathrm{mg} \mathrm{L}^{-1}$ suspended silica. 
The measured silica concentrations reported in the Figures and Tables were not corrected for the effect of temperature. Therefore, the measured silica concentrations really are in units of $\mathrm{gL}^{-1}$ at the stated temperature. To approximately convert these values to units of $\left.\mathrm{g}_{(\mathrm{kg} \mathrm{H}} \mathrm{O}\right)^{-1}$, multiply them by 1.05. The sampling syringe was always preheated by rapidly drawing brine in and out of it once or twice before actualiy taking the sample to be analyzed.

The molybdate yellow method is subject to serious interference by the traces of dissolved silica and inorganic phosphate that are usually present in tap water. To eliminate this problem, all solutions were prepared using water that was twice doubly delonized with mixed anionic/cationic ion exchange resins. The water coming out of our laboratory's "D. I. water" tap was already once doubly delonized; as a precaution, we sent it through our own column filled with mixed resin for the second double deionization step.

As in our previous work, we used the molybdate yellow procedure recommended by R. K. Iler (1979, P. 97). The molybdate reagent stock solution was prepared by mixing $100 \mathrm{~g}$ ammonium molybdate $\left(\left(\mathrm{NH}_{4}\right)_{6} \mathrm{Mo} 7 \mathrm{O}_{24} \cdot 4 \mathrm{H}_{2} \mathrm{O}\right), 47.0 \mathrm{ml}$ concentrated $\mathrm{NH}_{4} \mathrm{OH}\left(28 \% \mathrm{NH}_{3}\right)$ and water to make $1.0 \mathrm{~L}$ of solution. The final working molybdate reagent solution was prepared by mixing $100 \mathrm{ml}$ of the molybdate stock, $200 \mathrm{ml} 1.5 \mathrm{M} \mathrm{H}_{2} \mathrm{SO}_{4}$, and $500 \mathrm{ml} \mathrm{D.I.} \mathrm{water.}$

This working molybdate reagent solution was measured out in $40.0 \mathrm{ml}$ aliquots and placed in $50.0 \mathrm{ml}$ volumetric flasks. To determine dissolved silica, $1.0 \mathrm{ml}$ of the solution to be analyzed was added to the molybdate. reagent in the flask and the volume made up to $50.0 \mathrm{ml}$ with D.I. water. The flask was then Inverted and shaken three tImes, and the color allowed to develop for 3.5 minutes. (Shaking three times was found to improve the reproducibility of the results by ensuring more complete mixing.) The optical density was then measured at $400 \mathrm{~nm}$ using a double-beam spectrophotometer (Perkin-E1mer 550).

To determine total silica, a $1 \mathrm{ml}$ aliquot was drawn and placed in a 50ml plastic volumetric flask containing $1.0 \mathrm{ml}$ of $1.0 \mathrm{~N} \mathrm{NaOH}$. The flask was stopped, shaken, and set in a hot water bath for 10 minutes to allow the colloidal silica to be digested by the NaOH. After the colloldal silica had been digested, $40.0 \mathrm{ml}$ of the working molybdate solution and water to make the total volume up to $50.0 \mathrm{ml}$ were added, and the procedure continued as described above. 
In most of our experiments we "treated the brine" in one of two ways after 20 or 30 minutes had elapsed. One "treatment" was to increase the $\mathrm{pH}$ by adding NaOH. Another was to add a few $\mathrm{mg} \mathrm{L}^{-1}$ of one of a number of commercial synthet1c flocculants. In elther case, the chemical addition was followed by a few minutes of rapid stirring. After stirring was stopped, $\mathrm{pH}$ was determined again and periodic sampling resumed.

We also considered the possibility that the rapid stiring step itself, rather than the chemical addition that it accompanies, is what causes the colloidal silica to flocculate. This hypothesis was disproved by an experiment in which the brine was vigorously stirred for several minutes at the proper time without adding chemicals; this treatment was found to have no significant effect on the amount of silica that remained in suspension at the end of the experiment.

At the very end of the experiment the suspended sllica remaining in the brine was determined by an "absolute" method. First, about $150 \mathrm{ml}$ of the "brine" was decanted into a $200 \mathrm{ml}$ beaker, being careful to leave as much of the settled silica floc as possible behind. The decanted brine was held in a water bath at about $85^{\circ} \mathrm{C}$ for a few minutes to allow the small amount of coarse floc not removed by the first decantation step to settle out. Using a preheated $100 \mathrm{ml}$ pipette, a $100 \mathrm{ml}$ sample was then carefully withdrawn and placed in a preheated pressure filter funnel. Ordinarily, a $400 \mathrm{~nm}$ pore size polycarbonate membrane filter was used. The filter funnel was then sealed, and the fluid was driven through it with compressed nitrogen gas at about 1.3 bars gauge pressure.

The filter was then removed and placed in a plastic beaker with $3.0 \mathrm{ml}$ of $1.0 \mathrm{~N} \mathrm{NaOH}$ and heated in a bolling water bath for 10 minutes. After the silica was digested in this way, the filter was rinsed into the beaker and the contents of the beaker were then rinsed into a $50.0 \mathrm{ml}$ volumetric flask containing $40.0 \mathrm{ml}$ of the molybdate reagent for silica determination. Appropriate calculations then gave us the residual concentration of suspended silica in mg per liter of the "clarified" synthetic brine.

When implemented as described above, this technique is unable to determine suspended silica concentrations greater than about $32 \mathrm{mg} \mathrm{L}^{-1}$, because higher concentrations cause the spectrometer to go off scale. This is why "Final Suspended Silica" is reported as "> 32" in Tables 2 and 3 for some 
experiments. However, high concentrations of suspended silica were usually obvlous from the amount of floc accumulated on the filter. In such cases, the digested floc was diluted up to $50 \mathrm{ml}$ with D.I. water, and then a $1 \mathrm{ml}$ aliquot of this diluted solution was withdrawn, and the concentration of silica in it was determined in the usual way. This extra dilution step had the effect of extending the range of the method upward by a factor of fifty.

In cases in which the "brine treatment" was apparently successful, the "Final Suspended Silica" values were usually in the range 2 to $5 \mathrm{mg} \mathrm{L}^{-1}$. These suspictously repetitious values may be an artifact caused by slightly stirring up the floc during the second decantation step. Therefore, the amount of suspended silica remaining in the brine after a better executed settling process (as in a properly designed settilng tank in a pilot or commercial-size brine treatment facility) may prove actually to be less than 3 mg $L^{-1}$, all else being equal.

of course, this method can only determine the concentration of particles and flocs large enough to be stopped by a $400 \mathrm{~nm}$ filter. In practice, this probably means all particles and flocs whose greatest linear dimension exceeds some size considerably smaller than $400 \mathrm{~nm}$. Although the elemental colloidal particles are probably only between 20 and $100 \mathrm{~nm}$ in diameter under these conditions, the strongly flocculating nature of the "treated brine" probably ensures that most of the suspended silica is in the form of "flocs" large enough to be stopped by a $400 \mathrm{~nm}$ filter. Going to a finer filter did not seem warranted in the case of the laboratory tests, but probably would be in the case of pllot plant experiments.

Sometimes we also determined the floc settling rate. Thls was done by remixing the floc with the brine after the filtration procedure, quickly pouring the mixture into a graduated cylinder, and measuring the rate at which the floc settled with a stopwatch. The values obtained in this way were only approximate, because the rate of sedimentation was strongly affected by convection currents and the like. 
It is well established that increasing $\mathrm{pH}$ can destabilize colloidal silica suspended in salt solutions and cause it to flocculate or coagulate (Allen and Matif ev1C, 1969, 1970, 1971; Matijev16, 1972; Iler, 1975b; Weres, et al., 1980, Sections 2.21 and 22 ). Increasing the $\mathrm{pH}$ Increases the negative charge on the surface of the particles, and cations are adsorbed. These adsorbed cations serve as "bridges" between the particles, and this "bridging" effect is what causes the particles to adhere and flocculate. ""Coagulate" is probably more appropriate than "flocculate" in this particular case, but we use "flocculate" throughout this report to be consistent with common usage in the water treatment field.) The flocculating ability of cations increases rapldly with their charge. In Cerro Prieto brines, calcium is probably the main flocculating lon.

In flashed Cerro Prieto brines the conversion of dissolved sillca to colloidal silica is rapid, but removal of the colloidal silica from the brine by flocculation and settling is slow and incomplete. Therefore, the major task of preinjection brine treatment is to induce rapid flocculation and settling. Because Cerro Prieto brine contains a substantial amount of calclum, increasing the $\mathrm{pH}$ recommends itself as the simplest way to induce rapid flocculation.

Figure 1 semiquantitatively illustrates the effect of increasing the pH. In this experiment, the synthetic, brine was originally constituted with a $\mathrm{pH}$ of about 7.3 , and allowed to sit undisturbed for 25 minutes to let the concentration of MAS to drop to a nearly steady state value. Next, the brine was briefly stirred, the floc was allowed to settle for two minutes, and the first two $1 \mathrm{ml}$ aliquots were withdrawn to determine the concentration of suspended silica by the differential method. Then a small amount of $1 \mathrm{~N} \mathrm{NaOH}$ was added to Increase the $\mathrm{pH}$. After brief additional stiring the $\mathrm{pH}$ was measured, the floc was allowed to settle for 2 minutes without stirring, and two more aliquots were withdrawn for the determination of suspended silica. This cycle was repeated four more times to generate the rest of the points.

The data in Figure 1 are only semiquantitative in that the results obtained from such experiments are greatly affected by fine points of experimental design like the duration of settling, the size and shape of the 


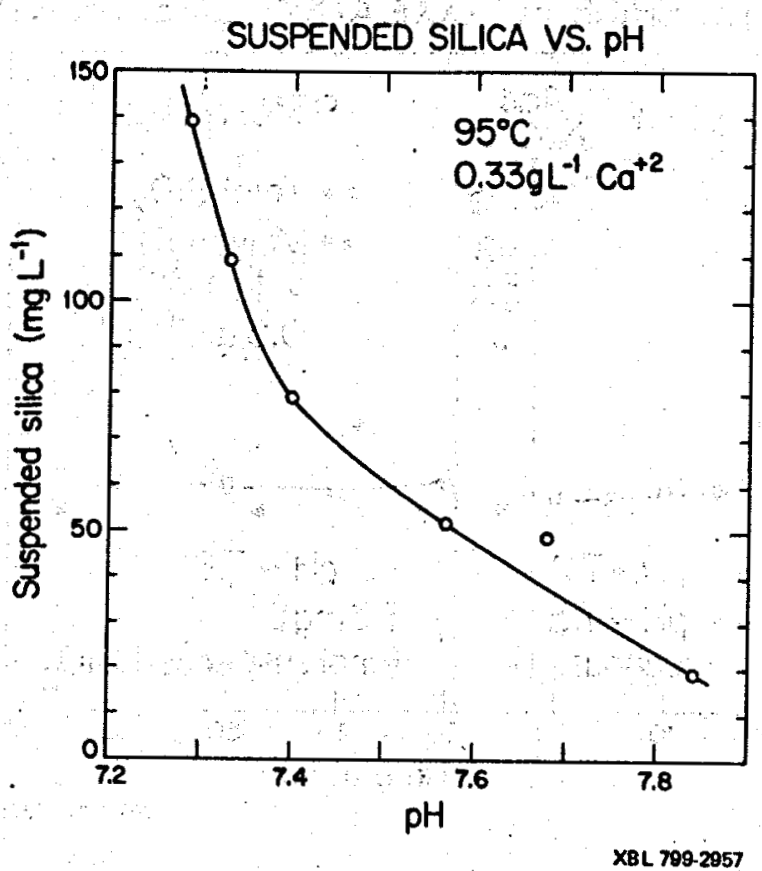

F1g. 1. The $\mathrm{pH}$ of this synthetic brine was progressively increased by adding $\mathrm{NaOH}$, and the suspended silica determined af ter each Increase.

reaction vessel, etc. However, it is obvious from Figure 1 that at $\mathrm{pH} 7.3$ flocculation is poor, and that increasing the $\mathrm{pH}$ to about 7.8 removes most of the colloidal silica from suspenston.

The full, detalled data obtained In two typical "brine treatment" experiments is presented in F1gure 2. In one of them (the solid symbols), the synthetic brine had an 1 itial $\mathrm{pH}$ of about 7.3 and was malntained that way throughout the duration of the experiment. In the other (open symbols), the synthetic brine Initially had a pH of about 7.2, and the pH was Increased by adding a small amount of $1 \mathrm{~N} \mathrm{NaOH}$ after 22 minutes. Except for the change In $\mathrm{pH}$ value and brief stirring in the second experiment, the two experiments were the same. The "High Ca" synthetic brine formulation was used in both. In both cases, a substantial fraction of the silica had already polymerized by the time that the first samples were taken for analysis. At this time there was also a faint white haze in the brine indicating the beginning of flocculation. (Unflocculated colloldal silica is Invisible to the naked eye at these concentrations. The very rapid initial stage of the polymeriza- 
SYNTHETIC BRINE FLOCCULATION EXPERIMENTS

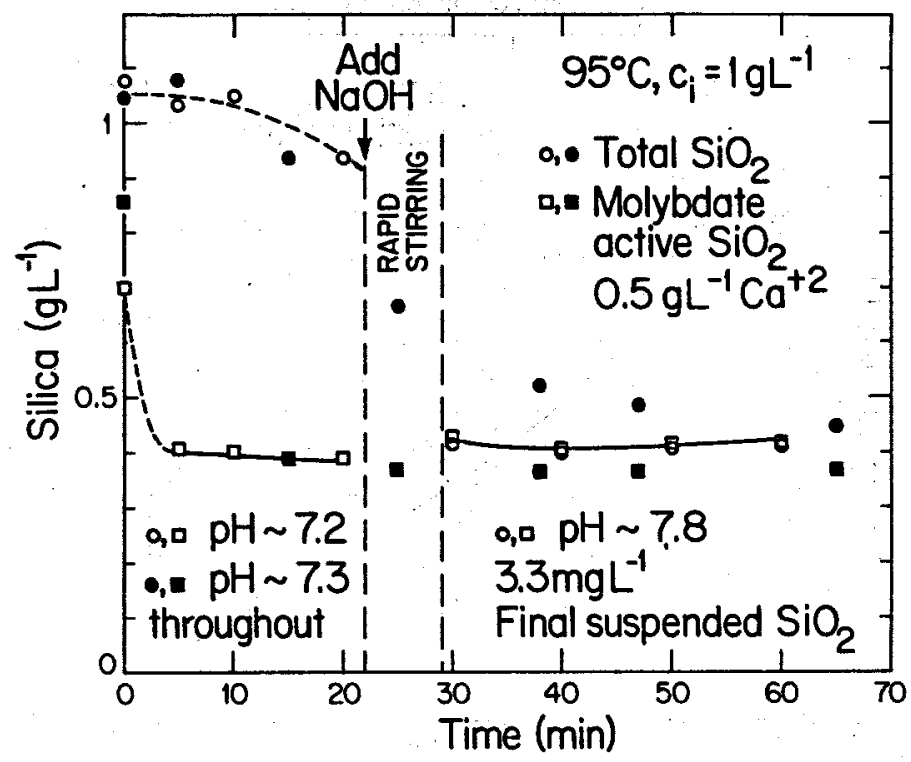

XBL 799-2976

Fig. 2. Solid symbols: brine not "treated." Open symbols: pH increased after 22 min. by adding $\mathrm{NaOH}$. In this and further similar Figures, silica concentrations not corrected for temperature effect. "High Ca" synthetic brine.

tion reaction had been completed by the time of the second point which was taken five minutes after the first. This means that a five-minute "aging time" would probably suffice to polymerize the silfica in a brine like this Instead of the 22 minutes allowed in this experiment.

The 20 minute total silica values show that, by that time, the colloidal silica had flocculated to the point that it was beginning to settle. Flocculation and settling were slightly more pronounced in the synthetic brine that had the higher initial $\mathrm{pH}$.

At 25 minutes the MAS concentration in the unmodified brine had already fallen to a "limiting" value. This value is somewhat higher than the equilibrium solubility level for bulk amorphous silica under these conditions which is about $0.33 \mathrm{~g} \mathrm{~L}^{-1}$. (See Weres, et al., 1980 , Sections 3.11 and 3.18 for detailed procedures to calculate the solubility of amorphous silica under various conditions.). That the value observed is higher than the "bulk solubiIity" value is due to the small size of the colloidal silica particles that are created under these conditions of rapid nucleation. Smal1 particles are more soluble than bulk AS, and their solubility determines the "1imiting" MAS concentration. 
Up to the point that the $\mathrm{pH}$ of the "treated" brine was increased, the MAS concentrations in the treated and untreated brines were equal to within experimental error. However, increasing the $\mathrm{pH}$ and stirring noticeably increased the MAS concentration in the "treated" brine. This is because Increasing the $\mathrm{pH}$ increases the solubility of amorphous silica, from about 0.33 to about $0.35 \mathrm{~g} \mathrm{~L}^{-1}$ in this case. That the post "treatment" MAS concentration was slightly above the corresponding equilibrium solubility value for bulk AS was again due to the greater solubility of small particles. If real, the apparent slow Increase of MAS concentration in the modified. brine toward the end of the experiment is probably due to continuing re-equilibration of the colloldal silica with its chemically modified environment.

The partial redissolution of the colloidal silica during and, perhaps, after the flocculation process is a desirable phenomenon from the practical point of view. It means that if the clarified brine is separated from the floc quickly enough, the small amount of collofdal sllica remaining in the brine will probably redissolve completely, if given enough time to do so. The final value of $3.3 \mathrm{mg} \mathrm{L} \mathrm{L}^{-1}$ suspended $\mathrm{SiO}_{2}$ was determined by the filtration technique. As discussed"in Section 3, even this small value may be due to the difficulty of achieving good settling in a small container rather than to imperfect flocculation.

The MAS concentration at the end of this experiment was about $0.42 \mathrm{~g} \mathrm{~L}^{-1}$, which is still above of the equilibrium solubility of silica under the given conditions. This means that the brine will slowly deposit vitreous silica on any surface with which it comes into contact. Our best estimate of the molecular deposition rate, as calculated using the methods presented by Weres et al. $(1980$, Section 3.14$)$, is about 5 micrometers year ${ }^{-1}$. This may or may not be small enough to avold injectivity decline over the life of an injection well, depending on the pore size in the recelving formation and the extent of fracture permeability. It would not effect fracture permeability, but might damage pore permeability if the pores are small enough.

Other experiments have shown that the floc produced by increasing the $\mathrm{pH}$ settles at a rate of about $1 \mathrm{~mm} \mathrm{sec}-1$, and that its volume after having settled for about $100 \mathrm{sec}$ is about 10 percent of the Initlal total volume of the brine. Its volume would probably be considerably smaller if it were allowed to settle for a longer period of time, as would be the case in an actual settling tank. 
Experiments with initial dissolved silica concentrations of 0.8 and 0.9 $\mathrm{g} \mathrm{L}^{-1}$ gave essentially the same results, except that the decline in MAS concentration to "steady state" values required the full 20 minutes with. the lower initial concentrations. (See Table 2.)

Similar experiments performed using the "Low $\mathrm{Ca}$ " synthetic brine gave the same results. (See Fig. 3 and Table 3.).

In one experiment $0.05 \mathrm{~g} \mathrm{~L}^{-1}$ of well-dispersed bentonite clay was added at the beginning. In spite of this, the "treated" brine was clear and the final suspended silica concentration was as low as usual. This suggests that the amorphous silica takes the clay particles with it when it flocculates and settles out. We conclude that this process may give brine that is completely free of all suspended solids, even if solids other than amorphous silica are initially present in it.

In these experiments sodium hydroxide was used to increase the $\mathrm{pH}$ as a matter of convenience. In practice, lime (calcium oxide or hydroxide) would be used because it is by far the cheapest base available. We estimate that only about $37 \mathrm{mg} \mathrm{L}^{-1}$ of calcium hydroxide would be needed to raise the pH to 7.8. (See Section 11.)

Rothbaum and Anderton (1975) have pilot tested a process for removing both suspended and dissolved sllica from the brines at Wairakei and Broadlands by adding a large amount of lime to them (up to $700 \mathrm{ppm} \mathrm{CaO}$ ). The silica was precipitated out as an amorphous calcium silicate. Adding lime in quantities as small as is proposed here apparently was not effective in flocculating the suspended silica because the brines in these two fields are of much lower salinity than that at Cerro Prieto, and contain much less calcium. Sodium hypochlorite was also added to the brines, and this caused the arsenic in it to precipitate out with the silica. All in all, this is basically a different process from the one proposed here. 
SYNTHETIC BRINE FLOCCULATION EXPERIMENTS

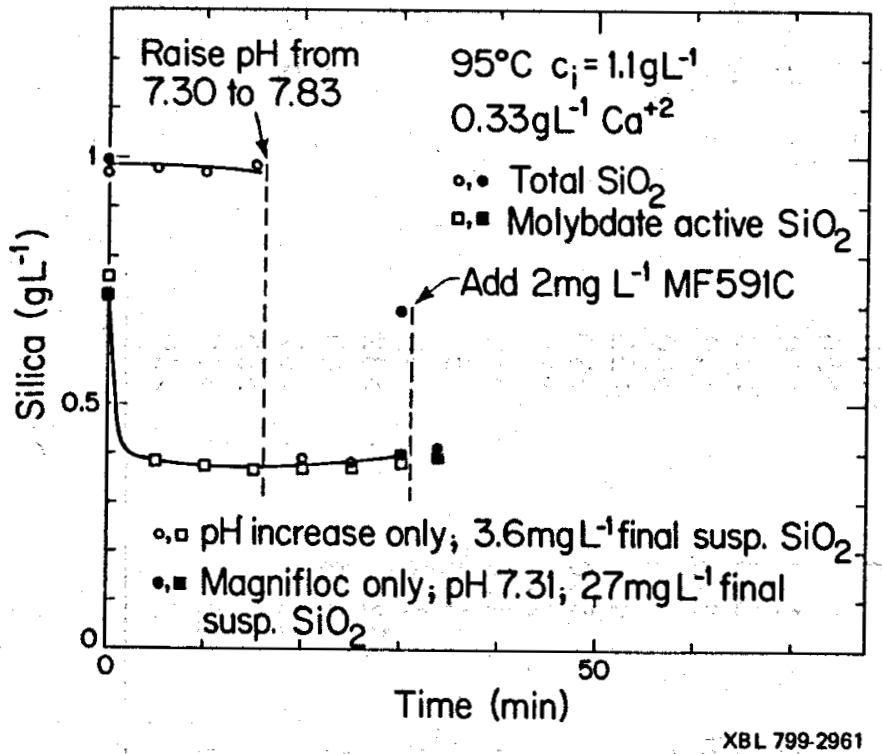

Fig. 3. "Low Ca" synthetic brine. Comparison of $\mathrm{pH}$ increase and addition of Magniflod $591 \mathrm{C}$.

Cationic polymers are known to be effective flocculants of colloidal silica. So are quaternary amines with long side chains (general formula: $\left.\mathrm{NR}_{4} \mathrm{X}^{-1}\right)$. For a discussion of the general principles involved, see Iler (1973, pp. 53-63) and Iler (1979, pp. 384-396).

A variety of synthetic organic flocculants were obtained from three manufacturers and tested. The results of these experiments are summarized in Tables 2 and 3 . The flocculants tested are listed and briefly described in Table 4. The detalled results of two synthetic brine experiments with synthetic flocculants are presented in figures 3 and 4.

The experiments in this series were like those discussed in section 4, except that the requisite amount of the synthetic flocculant was added to the synthetic brine with stirring after about 30 minutes instead of NaOH.

The most important data in Tables 2 and 3 are the "Final suspended Silica" values determined at the end of the experiment by the filtration method, but these values cannot be considered in isolation. The "Final suspended Silica" values for the first two experiments in Table 2 ("untreated brines") are low, but only because of the abnormally long time that these experiments were 
TABLE 2

Flocculation Experiments with High Ca Synthetic Brine

\begin{tabular}{|c|c|c|c|c|c|c|c|c|}
\hline Date & Flocculant & $\begin{array}{l}\text { Quantity } \\
\text { Used }\end{array}$ & $\begin{array}{c}\text { Initial } \\
\mathrm{SiO}_{2}\end{array}$ & $\begin{array}{c}\text { Intitial } \\
\mathrm{pH}\end{array}$ & $\begin{array}{l}\text { Suspended } \\
30 \mathrm{~min} \text {. }\end{array}$ & $\begin{array}{l}\mathrm{SiO}_{2} \text { at } \\
40 \mathrm{~min} .\end{array}$ & $\begin{array}{l}\text { Final } \\
\mathrm{SiO}_{2}\end{array}$ & $\begin{array}{l}\text { Suspended } \\
\text { at }(\min )\end{array}$ \\
\hline $12 / 12 / 78$ & none & - & 1000 & 7.40 & & $151^{\#}$ & 5.6 & $>96$ \\
\hline $12 / 11 / 78$ & none & - & 1000 & 7.17 & 321 & & 3.9 & $>100$ \\
\hline $2 / 2 / 79$ & $\mathrm{pH}$ raised & 7.77 & 800 & 7.41 & $459^{*}$ & 20 & 3.9 & $>50$ \\
\hline $12 / 19 / 78$ & pH raised & to 7.79 & 800 & 7.18 & $<10$ & $<10$ & 1.7 & $>70$ \\
\hline $1 / 5 / 79$ & $\mathrm{pH}$ ratsed & to 7.74 & 900 & 7.29 & 44 & 15 & 3.3 & $>60$ \\
\hline $12 / 21 / 78$ & pH ralsed & to 8.01 & 900 & 7.12 & $460^{*}$ & $27^{\#}$ & 3.5 & $>48$ \\
\hline $12 / 13 / 78$ & pH ralsed & to 7.75 & 1000 & 7.24 & 15 & $<10$ & 3.3 & $>60$ \\
\hline $6 / 11 / 79$ & MF $572 \mathrm{C}$ & $2 \mathrm{ppm}$ & 1100 & 7.23 & $69^{\#}$ & & $>34$ & $>33$ \\
\hline $5 / 30 / 79$ & MF $572 \mathrm{C}$ & $2 \mathrm{ppm}$ & 1100 & 7.20 & $<10$ & & 5.0 & $>30$ \\
\hline $1 / 10 / 79$ & MF $573 \mathrm{C}$ & $1 \mathrm{ppm}$ & 1000 & 7.25 & $449^{*}$ & 36 & 2.4 & $>50$ \\
\hline $1 / 9 / 79$ & MF $573 \mathrm{C}$ & $2 \mathrm{ppm}$ & 1000 & 7.27 & $576^{*}$ & $<10$ & 1.0 & $>60$ \\
\hline $4 / 27 / 79$ & MF $573 \mathrm{C}$ & $5 \mathrm{ppm}$ & 900 & 7.27 & $<10^{\#}$ & & 4.0 & 51 \\
\hline $1 / 8 / 79$ & MF $585 \mathrm{C}$ & $5 \mathrm{ppm}$ & 1000 & 7.17 & 34 & 13 & 1.8 & $>50$ \\
\hline $6 / 12 / 79$ & MF 591C & $2 \mathrm{ppm}$ & 1100 & 7.33 & $60^{\prime \prime}$ & & $>32$ & $>32$ \\
\hline $12 / 20 / 78$ & MF $1563 \mathrm{C}$ & $2 \mathrm{ppm}$ & 800 & 7.09 & $295^{*}$ & 26 & 5.3 & $>60$ \\
\hline $12 / 18 / 78$ & MF $2535 \mathrm{C}$ & $2 \mathrm{ppm}$ & 1000 & 7.23 & 64 & 31 & 13 & $>67$ \\
\hline $2 / 7 / 79$ & MF $836 \mathrm{~A}$ & $2 \mathrm{ppm}$ & 1000 & 7.34 & 78 & 58 & 28 & $>60$ \\
\hline $2 / 6 / 79$ & MF $836 A$ & $20 \mathrm{ppm}$ & 1000 & 7.25 & 39 & 40 & 22 & $>50$ \\
\hline $4 / 30 / 79$ & Calgon M 503 & $5 \mathrm{ppm}$ & 1100 & 7.31 & 18 & & 3.0 & $>30$ \\
\hline
\end{tabular}

Silica concentrations in ppm

$1 \mathrm{ppm}=1 \mathrm{mg} \mathrm{\textrm {L } ^ { - 1 }}$

MF - American Cyanamid Magniflod

"Point taken before "treatment"

\#point taken within 5 min. of stated time rather than at exactly that time. 
TABLE 3

Flocculation Experiments with Low Ca Synthetic Brine

\begin{tabular}{|c|c|c|c|c|c|c|c|c|}
\hline Date & Flocculant & $\begin{array}{l}\text { Quantity } \\
\text { Used }\end{array}$ & $\begin{array}{c}\text { Initial } \\
\mathrm{SiO}_{2}\end{array}$ & $\begin{array}{c}\text { Inftial } \\
\mathrm{pH}\end{array}$ & $\begin{array}{l}\text { Suspended } \\
30 \text { min. }\end{array}$ & $\begin{array}{l}\mathrm{SiO}_{2} \text { at } \\
40 \mathrm{~min} .\end{array}$ & $\begin{array}{l}\text { Final } \\
\mathrm{SiO}_{2}\end{array}$ & $\begin{array}{c}\text { Suspended } \\
\text { at (min ) }\end{array}$ \\
\hline $\begin{array}{l}4 / 13 / 79 \\
4 / 10 / 79 \\
4 / 11 / 79 \\
4 / 17 / 79 \\
5 / 31 / 79 \\
6 / 4 / 79 \\
6 / 1 / 79 \\
4 / 24 / 79 \\
4 / 18 / 79 \\
6 / 5 / 79 \\
4 / 16 / 79 \\
6 / 5 / 79 \\
6 / 6 / 79 \\
5 / 1 / 79 \\
5 / 2 / 79 \\
5 / 2 / 79 \\
4 / 12 / 79 \\
4 / 20 / 79 \\
4 / 19 / 79 \\
4 / 11 / 79 \\
5 / 1 / 79 \\
4 / 25 / 79\end{array}$ & $\begin{array}{c}\text { none } \\
\text { none } \\
\text { pH raised } \\
\text { pH ra1sed } \\
\text { MF } 572 \mathrm{C} \\
\text { MF } 572 \mathrm{C} \\
\text { MF } 572 \mathrm{C} \\
\text { MF } 573 \mathrm{C} \\
\text { MF } 573 \mathrm{C} \\
\text { MF } 577 \mathrm{C} \\
\text { MF } 585 \mathrm{C} \\
\text { MF } 587 \mathrm{C} \\
\text { MF } 591 \mathrm{C} \\
\text { Calgon M } 57 \\
\text { Calgon M } 58 \\
\text { Calgon M } 59 \\
\text { Pur1Floc C3 } \\
\text { Separan CP7 } \\
\text { Separan CP7 } \\
\text { Separan CP7 } \\
\text { Separán CP7 } \\
\text { Separan CP7 }\end{array}$ & 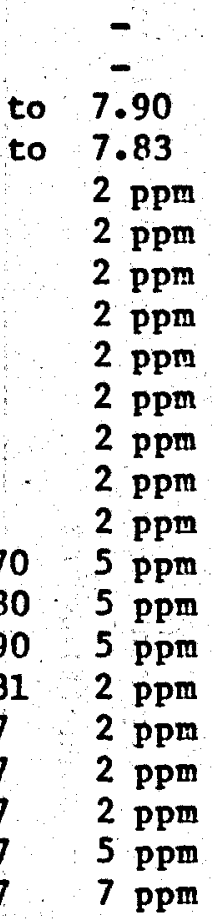 & $\begin{array}{r}1094 \\
1000 \\
1000 \\
1094 \\
1100 \\
1100 \\
1100 \\
900 \\
900 \\
1100 \\
1094 \\
1100 \\
1100 \\
1100 \\
1100 \\
1100 \\
1000 \\
900 \\
900 \\
1000 \\
1100 \\
1000\end{array}$ & $\begin{array}{l}7.24 \\
7.26 \\
7.29 \\
7.30 \\
7.22 \\
7.34 \\
7.32 \\
7.28 \\
7.27 \\
7.36 \\
7.32 \\
7.32 \\
7.31 \\
7.25 \\
7.23 \\
7.30 \\
7.27 \\
7.25 \\
7.41 \\
7.37 \\
7.30 \\
7.27\end{array}$ & $\begin{array}{l}253 \\
356 \\
<10^{\#} \\
<10 \\
617^{\star} \\
530^{\star} \\
278 \\
388^{\#} \\
499^{\star} \\
<10^{\#} \\
94^{\star} \\
295^{\star} \\
92^{\star} \\
599^{\#} \\
149 \\
58^{\#} \\
503^{\#} \\
230^{\star \#} \\
39^{\#} \\
18^{\star \#} \\
170^{\#}\end{array}$ & $\begin{array}{c}179 \\
294 \\
243^{\#} \\
31 \\
79^{\#} \\
144^{\#}\end{array}$ & $\begin{array}{c}27 \\
32 \\
2.5 \\
3.6 \\
177 \\
26 \\
303 \\
310 \\
32 \\
>32 \\
31 \\
>32 \\
27 \\
133 \\
82 \\
174 \\
30 \\
338 \\
0.7 \\
24 \\
21 \\
>31\end{array}$ & $\begin{array}{c}>60 \\
>60 \\
>34 \\
>30 \\
>45 \\
>40 \\
>30 \\
65 \\
52 \\
>36 \\
>30 \\
>31 \\
>34 \\
>31 \\
>45 \\
>30 \\
>32 \\
>28 \\
>44 \\
>33 \\
>28 \\
>35\end{array}$ \\
\hline
\end{tabular}

Silica concentrations in ppro

$1 \mathrm{ppm}=1 \mathrm{mg} \mathrm{L^{-1 }}$

MF = American Cyanamid Magniflod

Puriflod $B$ and Separan ${ }^{B}$ are Dow products

"Point taken before "treatment"

"Point taken within $5 \mathrm{~min}$. of stated time rather than at exactly that time. 
TABLE 4

Synthetic Flocculants Tested

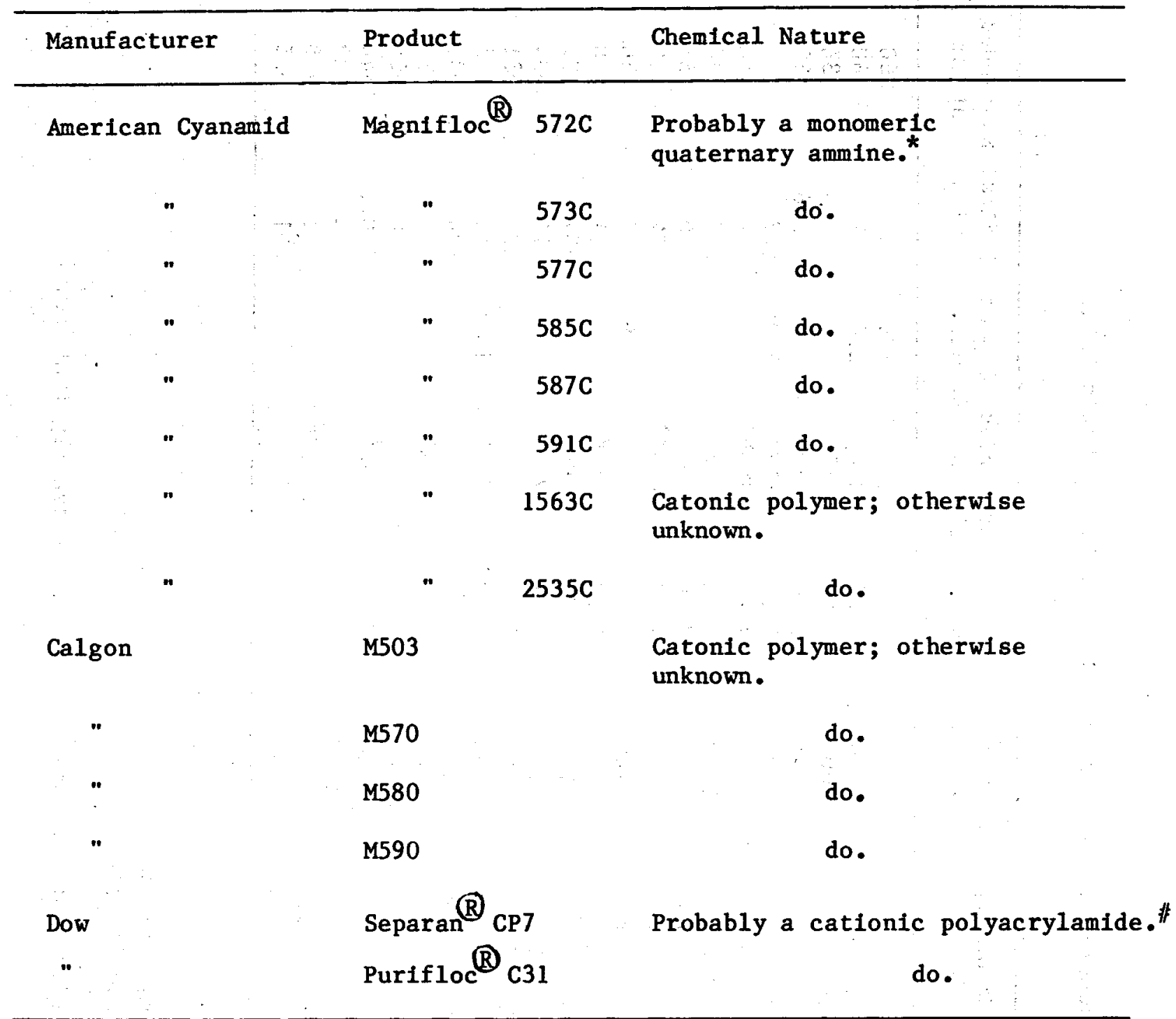

* The American Cyanamid product literature did not Identify the chemical nature of their products. However, the Magniflod $500 \mathrm{C}$ series products are stated to be of low molecular weight, and a shipping label on a package of samples we received identified the contents as quaternary ammonium compounds.

\#The Dow product literature stated that most of the products, in the Separan $\mathbb{B}$ and Puriflocis series belong to this chemical class. 
SYNTHETIC BRINE FLOCCULATION EXPERIMENT

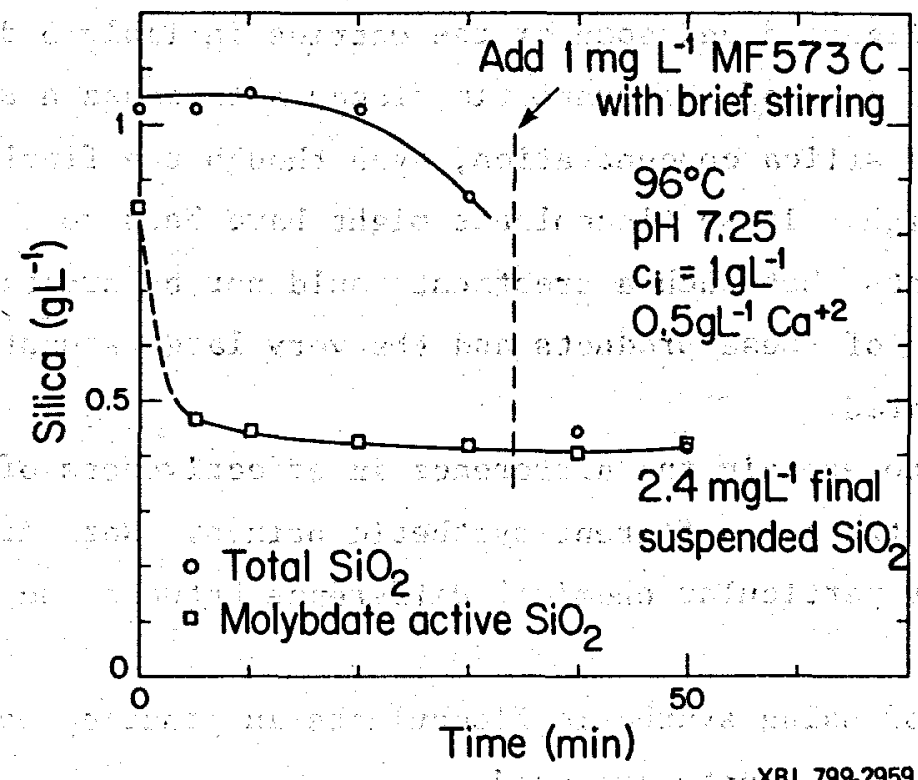

Fig. 4. "High Ca" synthetic brine. Effect of Magniflod( $573 \mathrm{C}$.

allowed to run. A treatment time this long would probably not be acceptable in practice. The 30- and 40-minute suspended silica values determined by the differential method are high, and the slow, steady decline of suspended silica concentration in the second experiment is shown in Figure 2 (solid symbols). The suspended silica concentrations In "untreated" low $\mathrm{Ca}$ synthetic brines likewise did not drop to acceptable values in a reasonable time (Table 3 ).

Raising the brine pH to about 7.8 quickly reduced the suspended silica concentration and gave a final value below $5 \mathrm{mg} \mathrm{L}^{-1}$ In all cases, both with the High and Low $\mathrm{Ca}$ synthetic brines (Tables 2 and 3 and Figures 2 and 3 ).

With the High $\mathrm{Ca}$ synthetic brine several of the synthetic flocculants gave generally promising results. Magniflod (B) $573 \mathrm{C}$ appears to be the most promising of them. Of the flocculants tested with the High Ca synthetic brine, only Magniflod 836A, which is an anionic polymer, was confirmed to be definitely ineffective.

As 18 evident from Table 3 and Figure 3 , synthetic flocculants in the concentrations used did not give good results with the Low $\mathrm{Ca}$ synthetic brine. The one low final suspended silica value obtained with Dow Separan $(\mathbb{R}) \mathrm{CP}$ was probably anomalous, because we were unable to reproduce it despite four 
attempts to do so. Figure 3 and some of the entries in Table 3 do, however, suggest that at least some of the synthetic flocculants cause a significant decrease in suspended silica concentration, even though the final values were still unacceptably high. These flocculants might have been more effective if added in larger amounts, but such a treatment would not be practical given the relatively high price of these products and the very large amount of water that needs to be treated.

We were unable to explain the difference in effectiveness of the synthetic flocculants with the two different synthetic brines. Nor were we able to correlate it with any particular chemical difference between the two synthetic brine compositions.

The advantages of using synthetic flocculants in practice would be:

1) relatively small amounts are used,

2) the only preparation they need prior to use is dilution with clean water to about $1 \%$ concentration, and

3) they cannot cause the precipitation of carbonate minerals as increasing the $\mathrm{pH}$ might.

Their disadvantages are:

1) most of them are expensive,

2) they slowly decompose, especially at high temperature,

3) they do not increase the solubility of silica as lime does, and

4) they are speclalty products that might not be conveniently and reliably avallable for use at Cerro Prieto.

The advantages of using lime are:

1) it is very cheap and universally available, and

2) it increases the solubility of silica in the treated brine. The disadvantages of using lime are:

1) increasing the $\mathrm{pH}$ might induce the precipitation of carbonate minerals (see Section 11). or of an amorphous calcium silicate phase, and

2) the equipment used to produce lime milk or gel from quicklime is somewhat complicated and expenstve. 
A few experiments were performed at Cerro Prieto to confirm the laboratory results. These experiments were essentially the same as those discussed In Sections 3 to 5, except that freshly collected samples of actual geothermal brine were used instead of synthetic brine. Also, when the brine pH was raised, a nearly saturated solution of calcium hydroxide was used for this purpose instead of sodium hydroxide.

These experiments were performed at the CFE Laboratory at Cerro Prieto with the help of J. Fausto L. of CFE. Brine from Cerro Prieto wells M-14 and M-30 was used because these wells are conveniently near to the laboratory. The brine from $M-30$ is considered to be more representative of the field as a whole.

We11s $M-14$ and $M-30$ are both producing wells that were steadily producing steam and brine when these experiments were performed. These wells (and all others at Cerro Prieto) have a special, small-diameter, brine-sampling line and miniature Webre separator connected to the wellhead. When this system was first turned on, brine was allowed to flow through it for at least 20 minutes before sampling. The sample was collected in a vacuum bottle which had first been rinsed with hot brine three times to bring it up to brine temperature. Immediately after taking the sample the time and temperature were recorded, and the first two 1-ml aliquots for the determination of total silica and MAS were withdrawn and put into prepared plastic 50-ml flasks that contained. sodium hydroxide and ammonium molybdate reagent, respectively. The sample was then rushed to the laboratory by car. The time from sampling to laboratory was usually about 8 minutes. At the the laboratory, the whole sample was poured into a prepared beaker In a hot water bath, and two more 1-ml aliquots were withdrawn for silica analysis.

The colloldal silica that formed in the brine taken from M-30 usually began to flocculate and settle by the time that the brine was poured into the beaker. This is 11lustrated in Figure 5, which presents the results of an experiment with $M-30$ brine that was not "treated." The amount of silica that remained in suspension after 30 minutes was $10 \mathrm{w}$, but probably not low enough for reinjection. Figure 6 shows how well adding 1 ime water to $M-30$ brine removes the suspended silica. Adding $2 \mathrm{mg} \mathrm{L}$ of Magniflod(B) $573 \mathrm{C}$ to $\mathrm{M}-30$ 

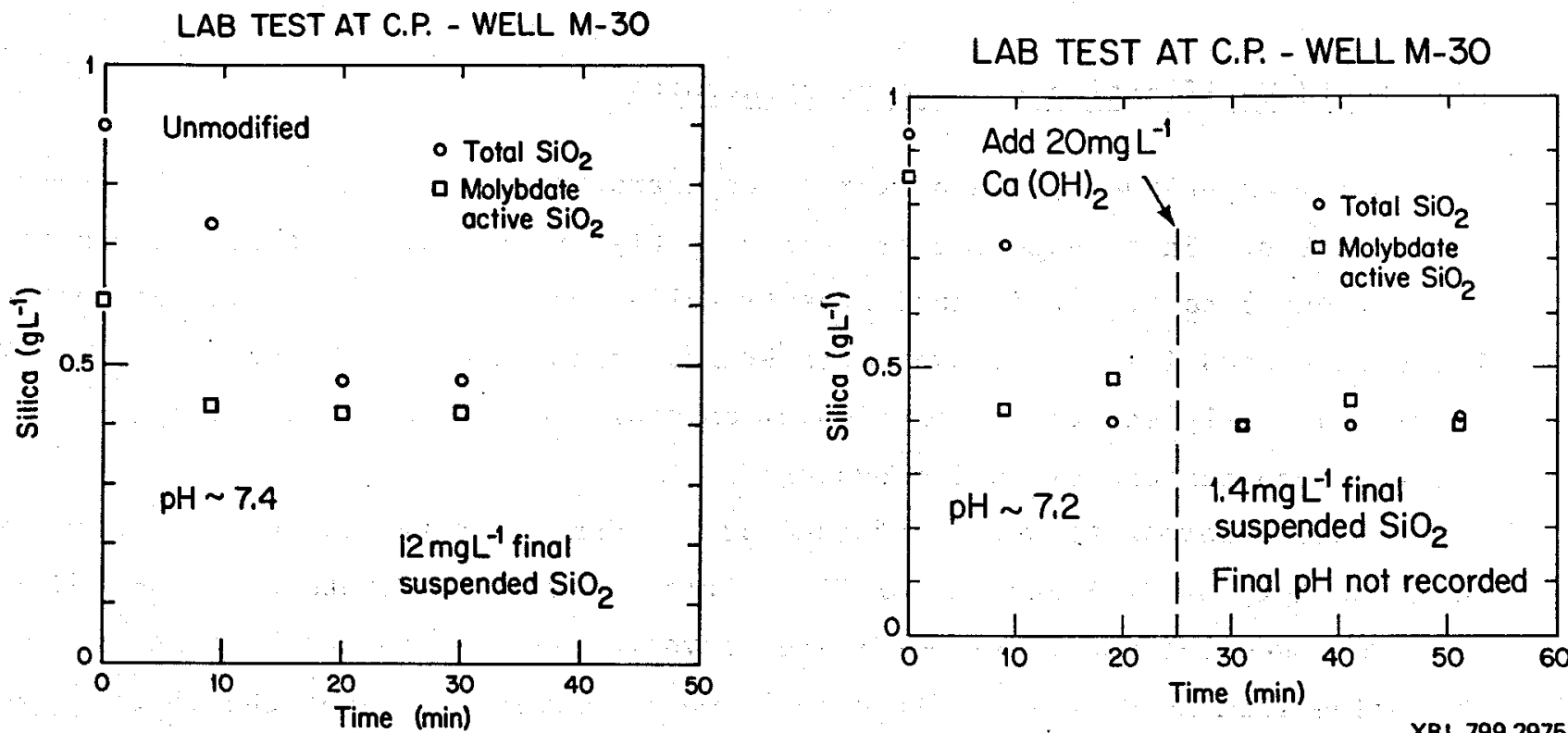

XBL 799-2974

Fig. 5. Experiment performed at Cerro Prieto using freshly flashed brine

F1g. 6. from Well M-30. Brine not "treated".

brine did not reduce the suspended silica to acceptable levels. (The results of these experiments are not shown here).

The colloidal silica in unmodifled brine from $\mathrm{M}-14$ does not flocculate even after the brine has been incubated for one hour. Figure 7 shows this and the effect of adding a small amount of lime water to M-14 brine. This small amount of lime was added by mistake, but there was no chance to repeat the experiment using more 1ime. Even this small amount of lime caused most of the colloidal silica to flocculate and settle out. Adding more lime, say $30 \mathrm{mg} \mathrm{L}^{-1}$, would probably reduce the suspended silica in $\mathrm{M}-14$ brine to acceptable levels. The very small difference between the pre- and post-treatment $\mathrm{pH}$ values in Figure 7 is probably due to experimental error.

Adding $2 \mathrm{mg} \mathrm{L} \mathrm{L}^{-1}$ of Magniflod $573 \mathrm{C}$ to $\mathrm{M}-14$ brine did reduce the suspended silica concentration to an acceptable level (Figure 8).

The volume and quality of the data we obtained in the fleld was reduced by the difficulty of working in an unfamiliar laboratory, time constraints, etc. However, the results obtained do seem to confirm the results of the laboratory work. Increasing the $\mathrm{pH}$ seems to work with brine from either well, while Magnifiod $573 \mathrm{C}$ works only with brine from $\mathrm{M}-14$; this is exactly the same pattern as that observed working with the two different synthetic brines. 
LAB TEST AT C.P. - WELL M-14

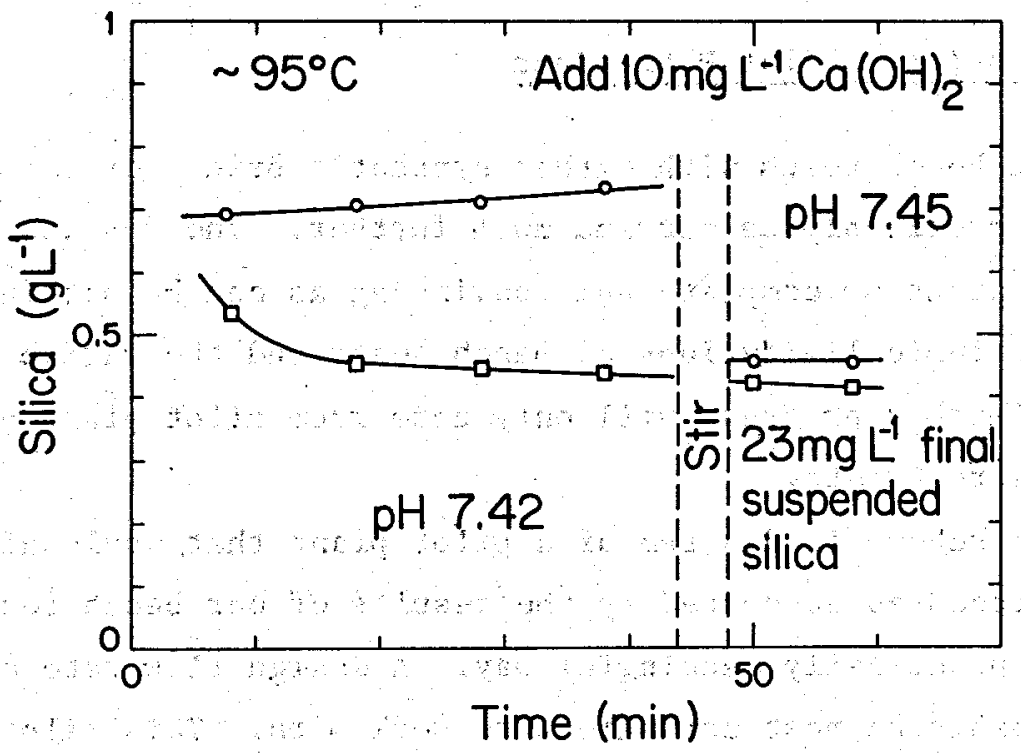

XBL 799-2960

F1g. 7. One or both $\mathrm{pH}$ values may be in error.

LAB TEST AT C.P. - WELL M-14

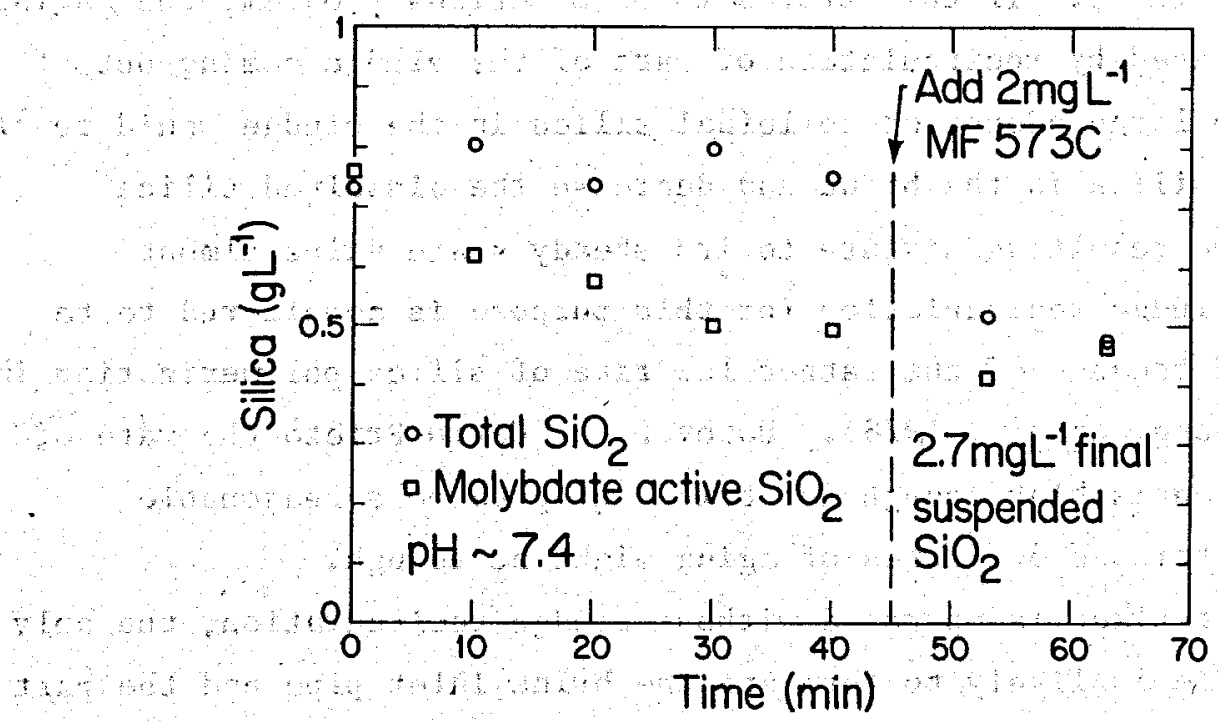

ith

F1g. 8. Effect of Magniflod $573 \mathrm{C}$ on brine from Cerro Prieto well M-14. 
We doubt that bench tests with either synthetic brines or samples of real brine can profitably be carried much further. The results reported here are probably about as complete and convincing as can be obtained in this way, given the intrinsic limitations of bench tests and the variability of natural brines. Further progress will only come from pilot plant experiments in the field at Cerro Prieto.

Figure 9 is a schematic diagram of a pilot plant that would allow the brine treatment processes suggested by the results of our bench tests to be evaluated in a practically meaningful way. A design flow rate of 5 to 10 $\mathrm{m}^{3} \mathrm{hr}^{-1}$ would probably be most convenient to work with. This pilot plant resembles the one used by Rothbaum and Anderton (1975).

When operated without sludge recirculation, this pilot plant would closely reproduce the processes evaluated in our bench tests. As in the bench tests, the function of the brine aging step is to allow time for the dissolved silica to be converted to colloldal silica. However, partial flocculation and settling of colloldal silica in the aging tank could lead to problems with sludge accumulation there. If this proves to be a serious problem, the "aging step" could be replaced by recirculation of part of the sludge coming out of the clarifier. The large amount of colloidal silica in the sludge would react with the dissolved silica in the brine and decrease the dissolved silica concentration in the resulting mixture to its steady state value almost instantaneously. Sludge recirculation for this purpose is considered to be essential at Niland because of the rather low rate of silica polymerization in the brine there (Quong, et al., 1978). However, at Cerro Prieto the rate of silica polymerization is high enough for brine aging to be a reasonable alternative. As little as 5 minutes of aging might be enough.

When this pilot plant is operated without sludge recirculation, the only places in which scale is likely to form are the brine inlet pipe and the part of the aging tank nearest to 1t. The aging tank should be designed with this in mind. For example, it might be possible to design it in such a way that the incoming brine doesn't come into contact with any part of the tank until a few minutes after it enters the tank and is already relatively nonreactive. 
PROPOSED BRINE TREATMENT PILOT PL.ANT FOR CERRO PRIETO

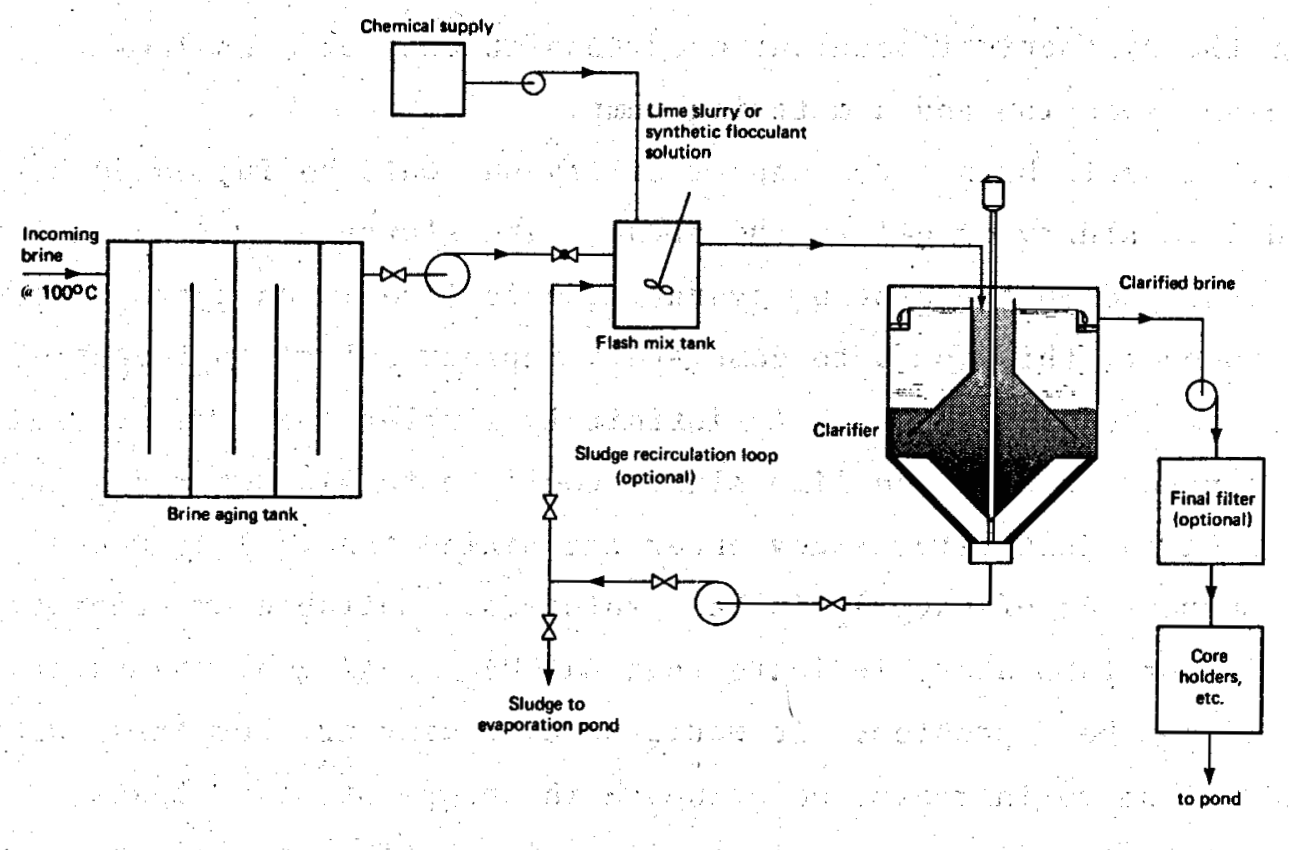

XBL $799-2849$

Fig. 9. Recommended brine treatment pilot plant facility for Cerro Prieto.

The sketch of the brine aging tank in Figure 9 is meant to be a view from the top. The brine flows from side to side around vertical baffles. A vertical laminar flow tank without baffles which the brine enters at the top and leaves at the bottom is another possibility. All that is really required is that the aging tank provide approximately plug flow reactor conditions, that sludge not accumulate in it, and that it be easy to clean.

In Figure 9, the clarifler, mixing tank, and sludge recirculation loop are shown as separate components. If a process that includes sludge recirculation were to be ultimately implemented, all three of these components could be replaced by a reactor-clarifier which combines the functions of all three In a single unit. Even if sludge recirculation is not required, there are clarifiers available that incorporate the function of the mixing tank as part of the clarifier. The "separate component" configuration shown In Figure 9 is recommended for the pilot plant because it allows maximum experimental flexibility and clearest separation of the effects of the various components on the overall performance of the process.

The pilot plant will require a dual chemical feed system to allow both $\mathrm{pH}$ increase and synthetic flocculant addition to be evaluated. The feed 
system for the synthetic flocculant need consist only of a storage tank for the flocculant solution and a metering pump.

In a full scale brine treatment facility $\mathrm{pH}$ would be increased by adding a hydrated lime slurry or gel to the brine. The slurry or gel would most 1ikely be produced on the spot by hydrating quicklime in an appropriate reactor. However, this would be completely impractical to implement on the small scale of the pllot plant. An infinitely simpler and more conventent method to generate a hydrated lime slurry would be to mix metered solutions of $\mathrm{NaOH}$ and $\mathrm{CaCl}_{2}$ just before they enter the mixing tank. This would produce a suspension of $\mathrm{Ca}(\mathrm{OH})_{2}$ in $\mathrm{NaCl}$ solution. Sultable experiments performed in our laboratory indicate that $\mathrm{Ca}(\mathrm{OH})_{2}$ scaling at the point of mixing would not be a problem. It would be even simpler, but less realistic, to use $\mathrm{NaOH}$ alone to increase the brine $\mathrm{pH}$ in the pilot plant tests.

We doubt that a final brine filtration step will prove necessary at Cerro Prieto, but it would be desirable to have that option available during the pilot plant work.

The floc produced by the processes discussed in this report is mostiy water, and may actually represent as much as 5-10 percent of the total volume of the incoming brine. Converting it to a concentrated sludge would complicate the process and equipment considerably. We recommend that it be simply disposed of by dumping it into the evaporation pond both in the pilot tests and in the ultimate commercial process . The existing evaporation pond at Cerro Prieto has more than enough capacity to handle the projected sludge output.

Drawing on related practical experience Quong, et al. (1978) at Niland, we recommend the following instrumentation and tests for monitoring the : performance of the process:

1) A flow-through turbidimeter to monitor the turbidity of the "clarified" brine. This instrument would allow suspended silica concentrations above about $10 \mathrm{mg} \mathrm{L}^{-1}$ to be instantly detected and continuous1y monitored in a semi-quantitative way. This capability would be very helpful in "coarse tuning" the operation of the pilot plant.

2) Some of the "clarified brine" should be pumped through a membrane filter. The filtration equipment should include a precise constant flow rate pump and instrumentation for continuous monitoring of the pressure drop 
across the filter. This equipment would allow the "formation plugging potential" of the clarifled brine to be determined via the method of Barkman and Davidson (1972).

3) The solid residue that collects on the filter should be analyzed to quantitatively determine the concentrations of suspended silica and calcium carbonate in the brine. (See Section 3 and Appendix 2, respectively, for the techniques.) There is no lower limit to the concentration of suspended solids that can be measured in this way. Simply flow enough brine through the filter to accumulate the amount needed for convenient analysis; this is typically only a few milligrams.

4) Clarified brine should be pumped through a sandstone core that is representative of the reservoir. The core holder should be instrumented to allow the permeability to be continuously followed as with the membrane filtration apparatus. High core confining pressure is not needed; a simple Hassler sleeve type core holder immersed in a bolling water bath would be completely adequate.

5) Cores used in the core-flushing experiments should be sectioned and studied petrographicallly afterwards.

6) Appropriate provision should be made to sample all streams in the pilot plant for analysis. Total silica, MAS and $\mathrm{pH}$ should be measured at all points, and complete mass balances determined. The brine aging tank and clarifier should each be provided with several sampling ports.

7) Corrosion monitoring coupons should be distributed throughout the system.

8) Quartz glass coupons should be distributed throughout the system to determine scale deposition rates. The use of quartz glass coupons would allow the scaling rates to be quickly and quantitatively determined without the complicating effects of simultaneous corrosion processes. The weight increases of the coupons would give the rates of scale deposition, and scale morphology could be determined by examining the specimens microscopically. (Laboratory experiments analogous to this are discussed in Sections 8,9 and 10.)

Both in the pilot plant and in the ultimate practical system, all equipment should be designed so as to keep alr out of the system. Steam jacketing the major vessels is recommended for this prupose. Particular 
efforts should be made to control heat loss from the small and complex "clarifled brine testing system" discussed above.

\section{S8 Scale Deposition from Synthetic Brines: Experimental Methods}

Extensive solid and semisolid deposits of nearly pure colloidal amorphous silica form throughout the existing waste water disposal system at Cerro Prieto. Field experiments with low pressure (1.e., second stage) steam separator units have shown that rapid deposition of amorphous silica scale occurs within the separators if they are operated with an exiting brine temperature below about $130^{\circ} \mathrm{C}$. This scale is solid and forms at a rate of up to about $1 \mathrm{~mm} \mathrm{day}^{-1}$ ( $\mathrm{R}$. Hurtado J., private communication and scale samples, 1978). These deposits consist of colloidal amorphous silica that has been more or less cemented by the molecular deposition of dissolved silica between the particles (see Section 10).

Silica scaling is presently only a minor problem at Cerro Prieto because the existing very simple waste water disposal system is not sensitive to it. However, second stage steam separators are and a preinjection brine treatment system would be as well. Therefore, the kfnetics of scale deposition and possible control methods are of interest. These things may be studied in the laboratory using synthetic brines precisely because scaling rates at Cerro Prieto are high enough to be conveniently measurable.

For scaling rate data to be meaningful, the scale must be deposited under steady state chemical conditions. This is clearly not possible in a "beaker test" like those discussed in Sections 3 to 5, and a continuous flow kinetic system must be used.

The system developed for this experiment is schematized in Figure 10, and several photographs of the apparatus are presented in Figure 11 . The compositions of the three solutions employed in most of these experiments are presented in Table 5, as well as the composition of the synthetic brine that is formed when two of them are mixed. This synthetic brine has the same calcium concentration as does the High Ca brine in Table 1, and the same sodium, potassium, and boron concentrations as the Low $\mathrm{Ca}$ synthetic brine in Table 1. It differs from both of the synthetic brines in Table 1 in that the concentration of barbital in it is $2-1 / 2$ times higher. 
SYNTHETIC SCALE DEPOSITION APPARATUS

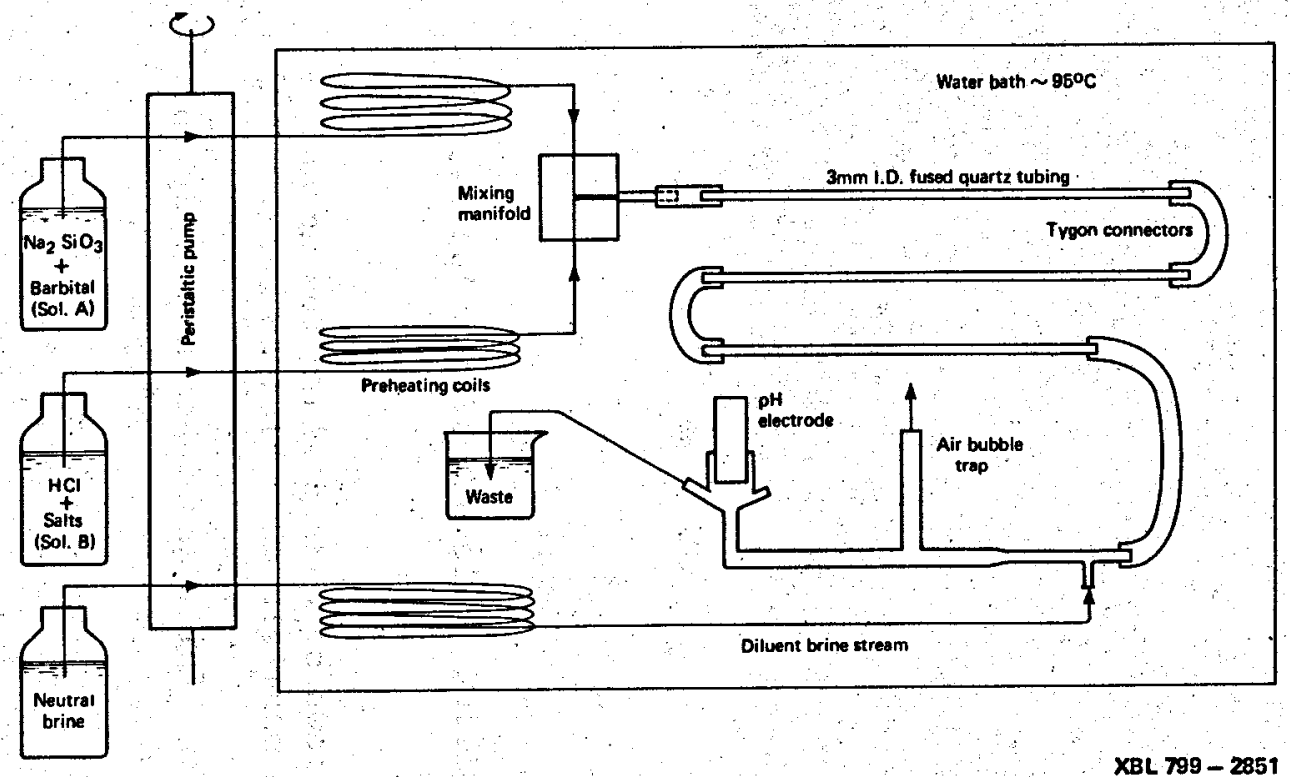

Fig. 10. There are actually four lengths of quartz glass tubing, and each of them consists of several short segments that are held together by Tygon $\mathbb{R}$ connectors. An early version of the "pH electrode manifold" is shown here.

The three solutions were pumped at equal rates by separate cassettes on a ten-channel Manostat Cassett@ pump. The cassettes were attached to the low speed drive shaft of the pump, and $1.5 \mathrm{~mm} I . D$. soft Tygon $\mathbb{B}$ tubing was used. In most of the experiments the flow rate of each solution was $23 \mathrm{ml} \mathrm{hr}^{-1}$, and the total synthetic brine flow rate was $46 \mathrm{ml} \mathrm{hr}-1$.

The whole kinetic system was immersed in a hot water bath whose temperature was nearly constant at about $95^{\circ} \mathrm{C}$. All of Its components were compactly mounted on a supporting rack made out of sllver soldered $3-\mathrm{mm}$ brass rod. The maximum dimensions of the rack were about $26 \times 16 \times 16 \mathrm{~cm}$.

After leaving the pump, the three solutions flowed through 1 meter long heat exchange coils made out of thin-walled Tefloon tubing with an inner diameter of about $1 \mathrm{~mm}$.

The synthetic brine was "constituted" and the silica polymerization and scale deposition reactions were initlated by mixing (preheated) solutions $A$ and $B$ in a mixing mantfold made out of a reflon ${ }^{B}$ block. Plugging of the mixing manifold by semisolid silica deposits was a recurrent problem. This problem was ultimately reduced to manageable proportions by 1 ) reducing the 


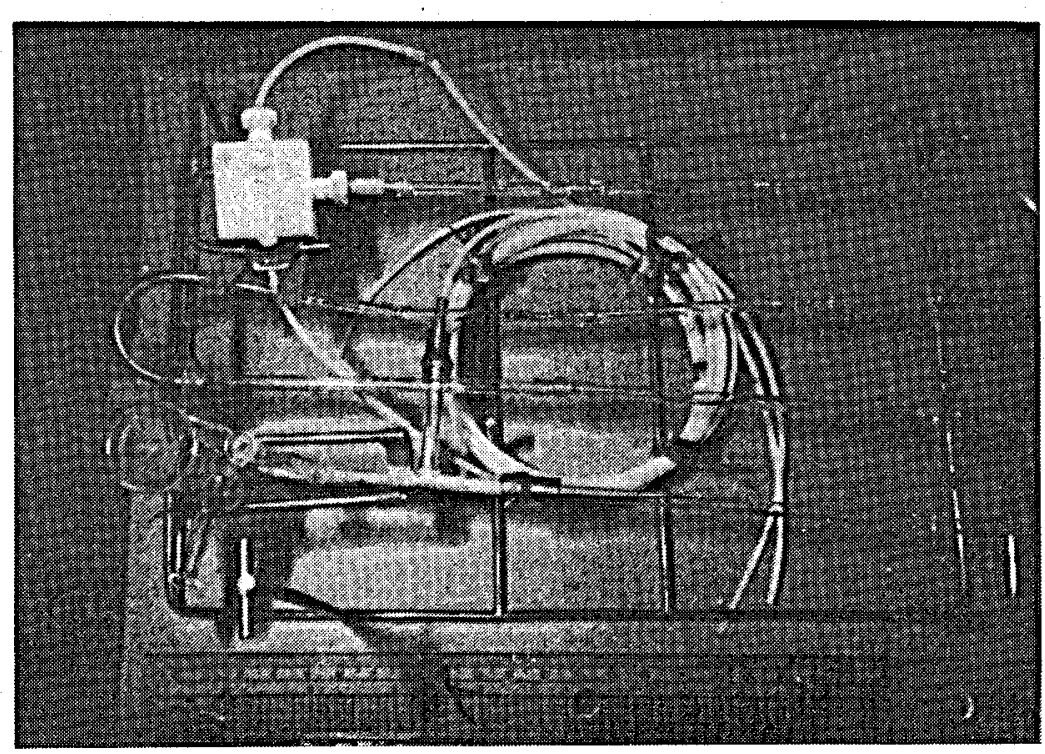

(a)

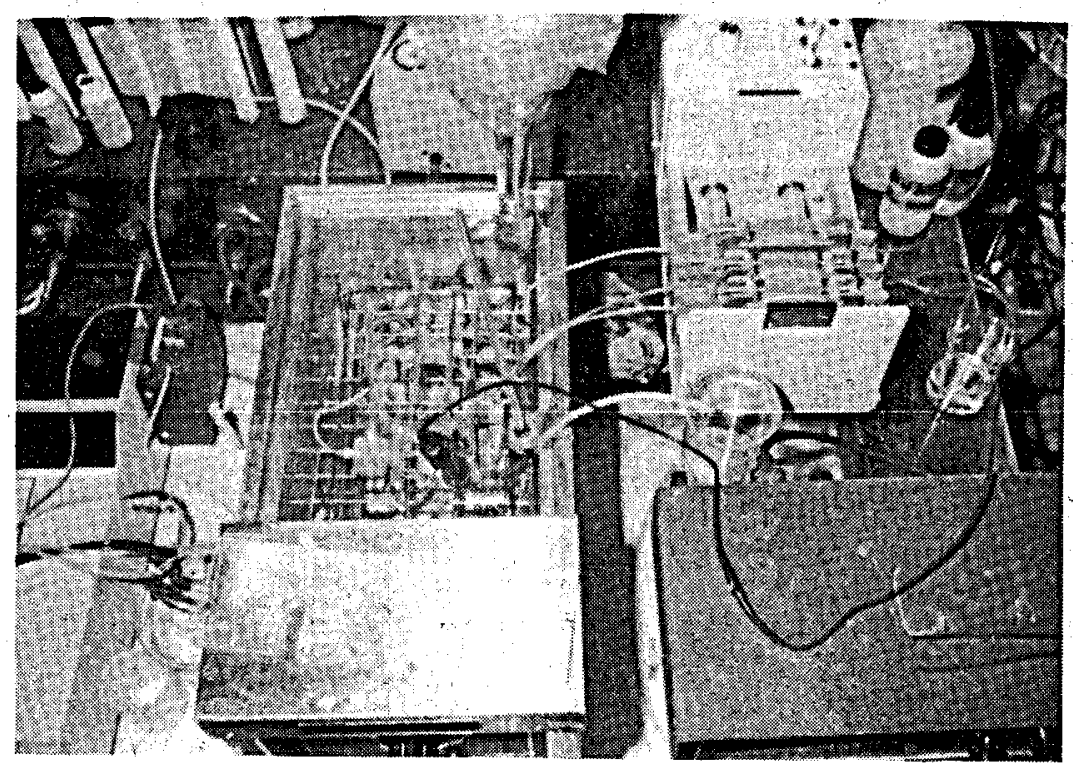

(c)

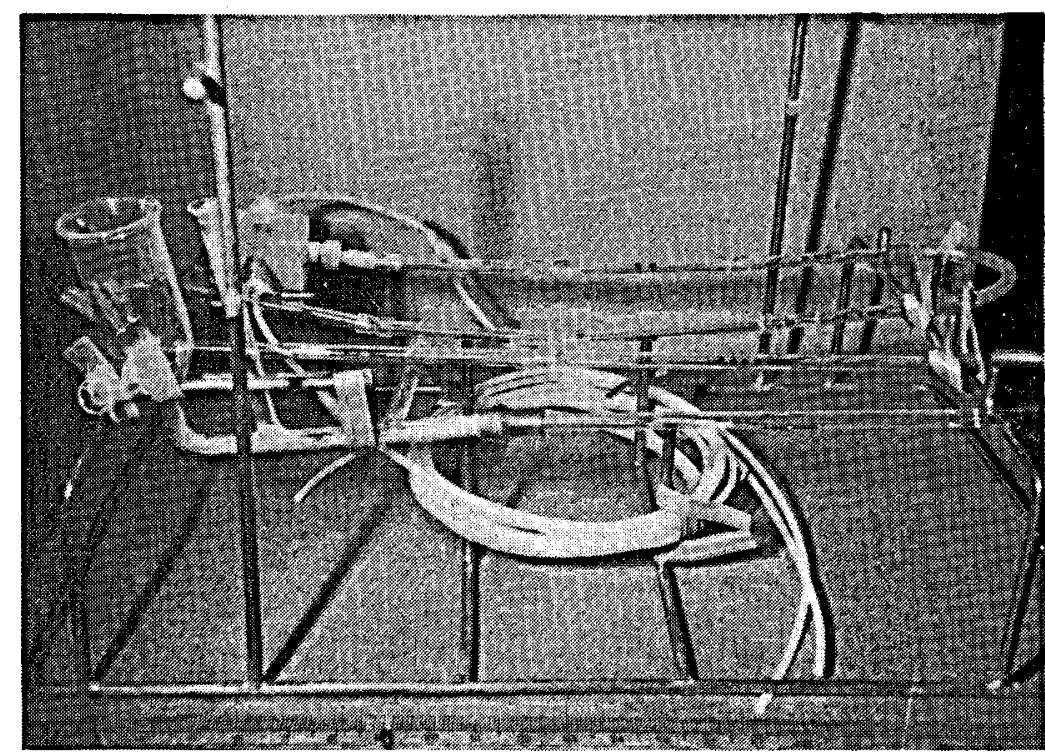

(b)

Figure 11

Synthetic Silica Scale Deposition Apparatus

(a), (b) Views of quartz glass tubing and $\mathrm{pH}$ manifold assembled on rack.

(c) Apparatus fully assembled and ready for startup. 
TABLE 5

Solutions Used 1n Scale Deposition Experiments

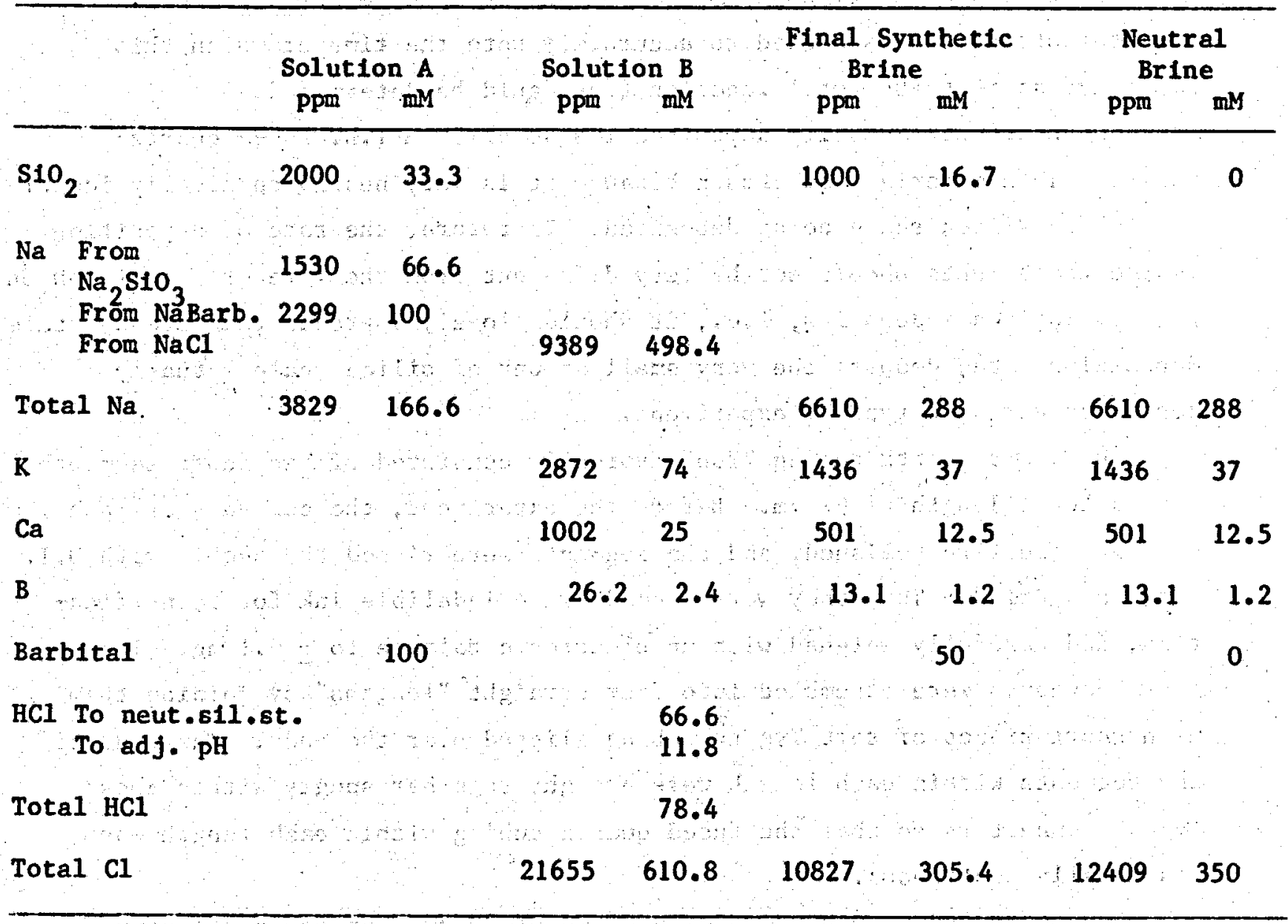


silica concentration in the synthetic brine to $1.0 \mathrm{~g} \mathrm{~L}^{-1}$ and 2) drilling out the exit channel of the mixing manifold to about $2 \mathrm{~mm} I . D$. Even so, the experiment often ended when the mixing manifold plugged up and one of the upstream tubing connections "popped" to relieve the pressure. Careful operator attention was needed to accurately note the time at which this happened, so that the total reaction time could be determined.

The scale was actually deposited Inside of $3 \mathrm{~mm}$ I.D. fused quartz tubing. This material was chosen because it is very nearly chemically identical to the silica scale being deposited. Therefore, the rate of deposition Inside these tubes should not be very different from the rate of deposition on preexisting scale deposits; i.e., it should closely approach the "steady state" deposition rate, despite the very small amount of silica scale actualiy deposited during a typical experiment.

The fused quartz tubing "run" typically consisted of ten short segments with a total length of $67 \mathrm{~cm}$. Before the experiment, the cut ends of each segment were fire polished, and the segments were rinsed thoroughly with D.I. water and dried. Then they were "coded" with indelible ink for identification, and carefully weighed with an electronic balance to $\pm 0.1 \mathrm{mg}$. These short segments were assembled into four straight "lengths" by joining them with short pieces of soft Tygon tubing slipped over the ends. The ends of the segments within each length were brought together snugly within these Tygon $\mathbb{B}$ connectors so that the fused quartz tubing within each length was essentially continuous.

One segmented length of $15 \mathrm{~cm}$ and two of $20 \mathrm{~cm}$, and one continuous length of $12 \mathrm{~cm}$ were used. (Only thrce lengths are shown in Figure 10 and their segmented nature is ignored for simplicity.) These particular lengths were chosen for , convenient assembly and handling. The straight lengths are connected by longer pieces of soft Tygor ${ }^{*}$ tubing, which is also used for connections elsewhere in the system. The Tygon $\mathbb{B}$ tubing used for this purpose has an inner diameter of about $2-1 / 2 \mathrm{~mm}$. The length of the flow path through each of the longer Tygon $(\hat{R}$ connectors between the lengths of quartz glass tubing was $5 \mathrm{~cm}$. 
All jolnts between the longer Tygon connectors and glass or Teflon $\mathbb{R}$ tubing were reinforced by wire ties wound around them. Also, the supporting rack was carefully designed to minimize forces on the connectors. These precautions were necessary because Tygo $\mathbb{B}$ softens in hot water and the connectors would have frequently slipped off otherwise.

The total length of the quartz glass tubing and Tygon connectors was $82 \mathrm{~cm}$. At a brine flow rate of $46 \mathrm{ml} \mathrm{hr}$, this gave a total transit time of about 7.1 minutes.

After leaving the quartz glass tubing, the synthetic brine flows through a glass manifold that holds the tip of a $\mathrm{pH}$ electrode. Before it enters the electrode compartment, the synthetic brine is diluted by one-third with the "Neutral Brine." Th1s solution is the same as the synthet1c brine except that it does not contain any silica or barbital (see Table 5). The purpose of diluting the brine at this point is to reduce the concentration of dissolved silica and, thereby, avold silica deposition on, and damage to, the glass membrane of the electrode. The "Neutral Brine" used for this purpose was formulated to resemble the synthetic brine in order to minimize the change in $\mathrm{pH}$ caused by dilution.

An "inverted $T$ " was bullt into the manifold to remove air bubbles. from the brine before it reached the electrode. This was necessary, because air bubbles inevitably formed in the solutions during preheating, and caused wild fluctuations in the $\mathrm{pH}$ reading if allowed to reach the electrode compartment. Both the main longltudinal member of the manifold and the air vent were made out of 3-mm I.D. glass tubing. A smaller alr vent diameter would have caused "burping," and the tube it was joined to could not have a smaller diameter than the vent.

The brine flowed into the electrode chamber through the bottom, up past the electrode's glass bulb, and out through a side port. In early versions of the manffold, another stde port was provided for a thermoelectric temperature sensor which directly read the brine temperature (rather than the water bath temperature). Brine temperature monitoring was abandoned after 1 was established that it was never more than $1^{\circ} \mathrm{C}$ lower than the water bath temperature, and the second side port was eliminated from later versions of the manifold. The annulus around the electrode was sealed off with two 0-rings. 
Maximizing the time resolution of the $\mathrm{pH}$ reading requires that the volume of the manifold be minimized by careful design. Its longitudinal member was only $8 \mathrm{~cm}$ long, and we were able to achieve a time resolution of. about one minute in the $\mathrm{pH}$ reading.

Devising adequate means of controlling and monitoring brine $\mathrm{pH}$ presented the major challenges in developing this technique. Some degree of varying mismatch between the pump channels pumping solutions $A$ and $B$ is inevitable. Because these solutions contain substantial concentrations of base and acid, respectively, pumping irregularities cause fluctuations in the $\mathrm{pH}$ of the resulting synthetic brine. Also, it was not possible to put the barbital in with the acid and salts and to "pretitrate it" because the constituent solutions were prepared and kept at room temperature; attempts to do so. inevitably caused precipitation of the sparingly soluble acid form of barbital. This is why a higher concentration of barbital was needed here than in the "beaker experiments" of Sections 3 to 5 , and why $\mathrm{pH}$ had to be continuously monitored.

A Lazar sealed $\mathrm{pH}$ electrode was used in this work. The $\mathrm{pH}$ electrode was allowed to preheat before the start of the experiment. It was calibrated by pumping a commercial standard pH 7 buffer solution (Mallinckrodt Buffer) through all three pump channels. After a stable signal had been achieved, the meter was set to the $\mathrm{pH}$ of the buffer at the bath temperature. The tubes were then rinsed off with water and set in the reactant and diluent solutions. Leaving a bubble in each of these feed lines allowed the operator to follow. the position of the reactants and note when they met in the mixing manifold. After the reactant solutions reached the mixing manifold the pump was adjusted to give the desired flow rate of $23 \mathrm{ml} \mathrm{hr}^{-1}$ per channel.

A typical experiment ran for $1-1 / 2$ to 2 hours. At the end of the experiment, the reaction tubes were removed and rinsed thoroughly to remove any loose silica. They were placed in an oven set at $110^{\circ} \mathrm{C}$ and allowed to dry overnight. When dry, they were weighed and the difference in weight before and after the reaction was the amount of silica deposited. This was . usually a few mflligrams per segment.

In a typical experiment, about $75 \mathrm{ml}$ of synthetic brine containing a total of about $75 \mathrm{mg}$ of $\mathrm{SiO}_{2}$ flowed through the system. About $10 \mathrm{mg}$ of this was typically deposited inside the quartz glass tubing. An unknown 
but probably much smaller amount was deposited inside the Tygon ${ }^{\mathbb{B}}$ connectors. Because only about 10-15\% of the total silica in the brine was deposited, it seems unlikely that the relatively large surface to volume ratio of the tubes significantly affected the results.

Finally, some of the tube segments were scored lengthwise with a diamond scribe on both sides and then carefully broken. Th1s procedure usually resulted in a few pieces suitable for microscopic examination and a small pile of crushed quartz glass.

\section{S9 Scale Deposition: Experimental Results}

A total of about twenty scale deposition experiments produced usable results. The range of brine $\mathrm{pH}$ values in these experiments was 6.95 to 7.50 .

The values obtained for scaling rate vs. position along the flow path for four experiments at $\mathrm{pH}$ near 7.35 are presented in Figure 12. Each point represents the average scaling rate within a segment of quartz glass tubing determined by dividing its weight gain by the product of its inside surface area and the duration of the experiment. The "distance along tube" is the distance along the flow path, Including the Tygor $(\mathbb{1}$ connectors, measured from the beginning of the first tube segment. The three connectors start at about the 15,40 and $65 \mathrm{~cm}$ positions, respectively. The symbol representing the scaling rate in a given tube segment is plotted at the position of the midpoint of that segment. Each value is the average of the deposition rate over the whole length of the given segment. The zero of the time scale is. slightly offset from that of the distance scale to account for the seven second transit time between the point of mixing and the start of the quartz glass tubing.

The dissolved silica concentration as a function of position along the tube is unknown. This means that the rate of molecular deposition cannot be calculated. However, $1 t$ is easy to determine that the rate of scale deposition is one or two orders of magnitude greater than the rate of

\footnotetext{
* See footnote on following page.
} 
Time from mixing $(\min )$

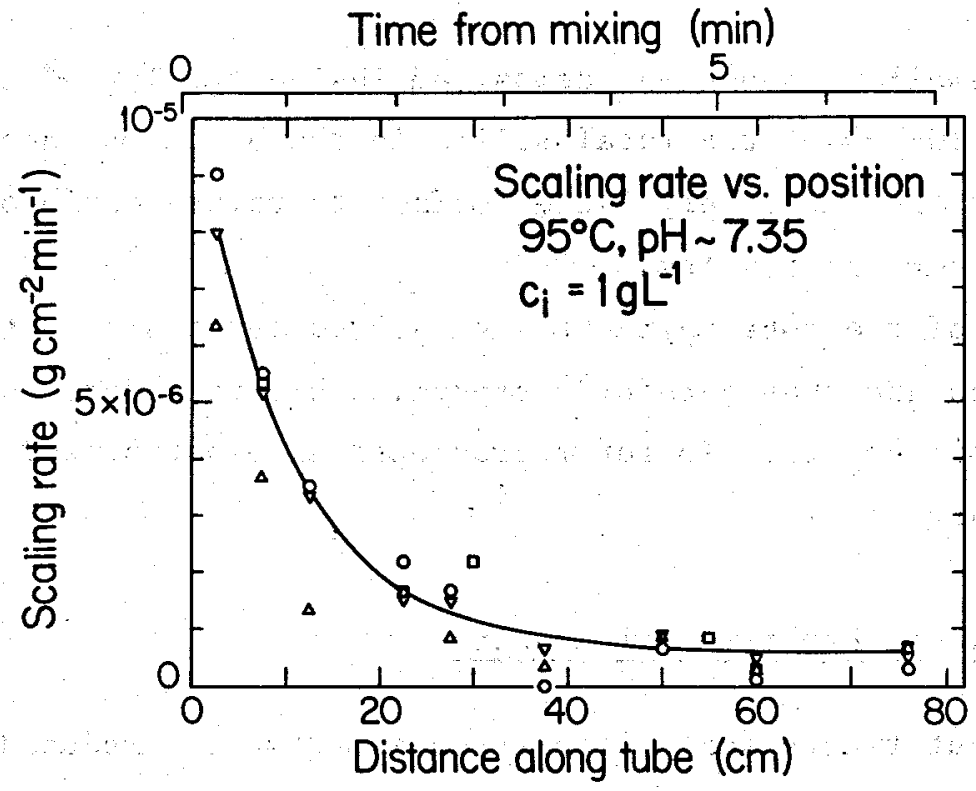

XBL 799-2964

Fig. 12. Experimentally determined scale deposition rates as a function of position along the quartz glass tube and the time from mixing.

molecular deposition of dissolved silica under similar conditions.* This conclusively demonstrates that the dominant mechanism of scale formation under these conditions involves deposition onto the tube wall of colloidal silica formed in the liquid phase.

The deposition rate is high at first, and drops off rapidly with time and distance along the tube. Comparing this data to the curves of MAS vs. time presented in Figures 2, 3 and 4 shows that the decrease in scaling rate is roughly parallel to the decrease in dissolved silica concentration. Because only a modest fraction of the colloidal silica that is formed in the brine is deposited as scale, the decrease in colloidal silica suspended in the brine with time cannot be the cause of the rapid drop-off in the deposition rate. We conclude the rate of molecular deposition must control the overall scaling rate under these conditions.

* By "molecular deposition" we mean the deposition of dissolved silica onto a solid surface one molecule at a time. See Weres, et al. (1980) regarding the nature and kinetics of this process. 


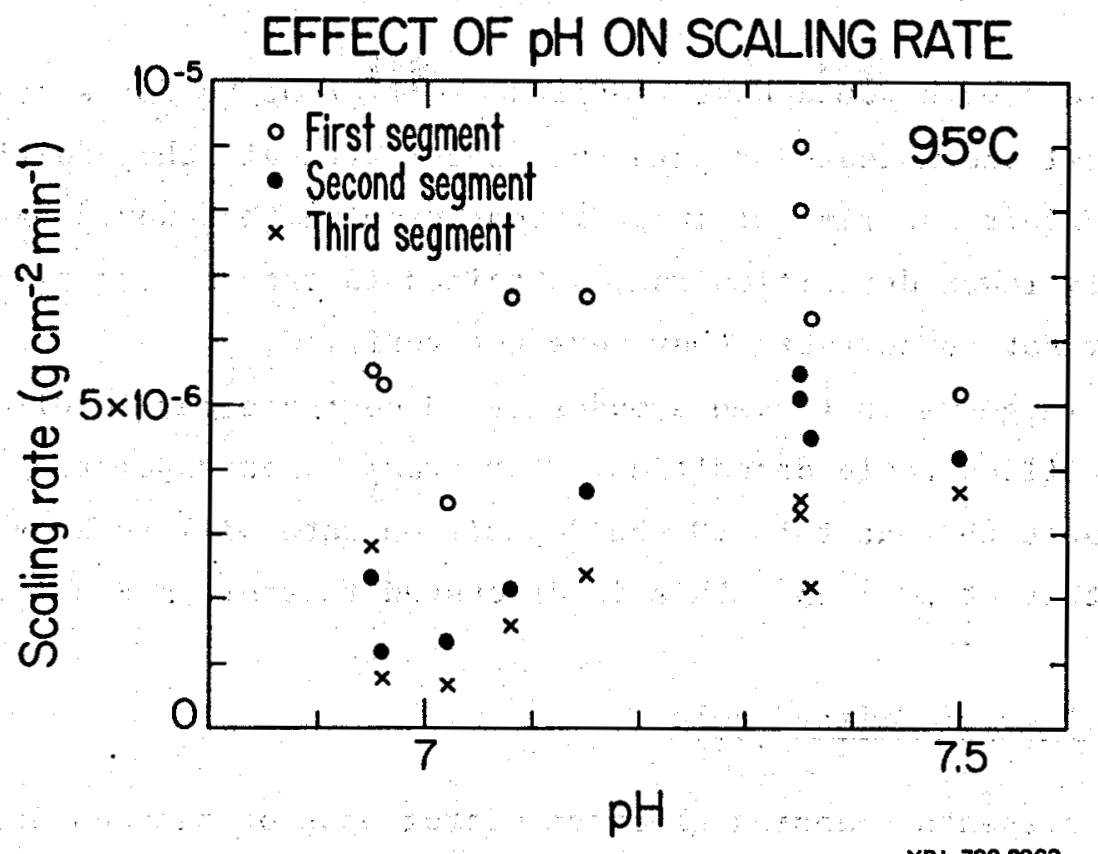

Fig. 13.

Almost certainly, the first step of scale deposition involves the attachment of colloldal silica particles and "clumps" formed in the liquid phase to the tube wall by electrostatic forces identical to those that cause flocculation in the liquid phase. The particles are then permanently attached and the deposit made solid by molecular deposition of dissolved silica between the particles. This model of the scaling process was originally proposed by Iler $(1973,1975$ a).

Practically speaking, Figure 12 shows that aging newly flashed brine for three to five minutes should suffice to greatly reduce the scaling rate further along in the system.

Figure 13 shows the effect of $\mathrm{pH}$ on the deposition rate in the first three tube segments. Between $\mathrm{pH} 6.95$ and 7.35 , the effect of $\mathrm{pH}$ on the deposition rate is comparable to its effect upon the rate of molecular deposition under similar conditions (see Weres, et al., Figure 3.4 or Table A3.2). Th1s means that the trend can probably be meaningfully extrapolated to at least moderately lower pH values. No experiments at pH values below 6.95 were attempted because of the inconveniently low scaling rates in this 
range. Also, such work would have required a different buffer system probably barbital and maleate or maleate alone - with all the additional developmental effort and risk of inconsistent results that would have entailed. The unexpectedly lower deposition rates obtained in the one experiment at $\mathrm{pH}$ 7.50 may or may not be correct; they were not verified.

Figure 13 suggests that even a moderate $\mathrm{pH}$ decrease may be effective in controlling silica scale deposition. For example, extrapolating the trend to $\mathrm{pH} 6.5$ suggests that at this $\mathrm{pH}$ the deposition rate will be only about one-fourth of that at $\mathrm{pH} 7.35$. This is discussed further in Section 11.

\section{S10 The Morphology of Silica Scale}

Figure 14 presents scanning electron micrographs of samples of silica deposits obtained from $\mathrm{R}$. Hurtado $\mathrm{J}$. of the IIE laboratory at Cerro Prieto. The samples were collected by IIE personnel during tests of low pressure steam separators, and all came from inside the test units. All three specimens are essentially pure $\mathrm{SiO}_{2}$. (This was determined using the micrsocope's energy dispersion spectroscopy attachment.)

Figure 14 (a) shows a soft and fluffy white powder. This is basically dried flocculated colloidal silica. There is little if any chemical cementation between the particles. The finest detail visible in the photograph is : on the scale of about $100 \mathrm{~nm}$, and this suggests that the ultimate particle size is about this or smaller. This material most closely resembles the flocculated silica produced in the silica removal experiments discussed in Sections 3 to 5 .

Figure 14 (b) shows the broken edge of "typical" solid silica scale. As is commonly the case at Cerro Prieto and elsewhere, this specimen was stratified, with the macroscopic appearance of the various layers ranging from white and porous to nearly vitreous and dark grey. This material consists of densely packed collold silica particles that have been cemented into a solid by molecular deposition of dissolved silica between them.

Figure 14 (c) shows a sample that has been so thoroughly cemented that it is completely glasslike and retains no trace of its colloidal origin. We know that it did not form by molecular deposition alone because that process is too slow to form scale deposits in a short time under these conditions. Also, 
Figure 14

Silica Deposits from Low Pressure Steam Separators

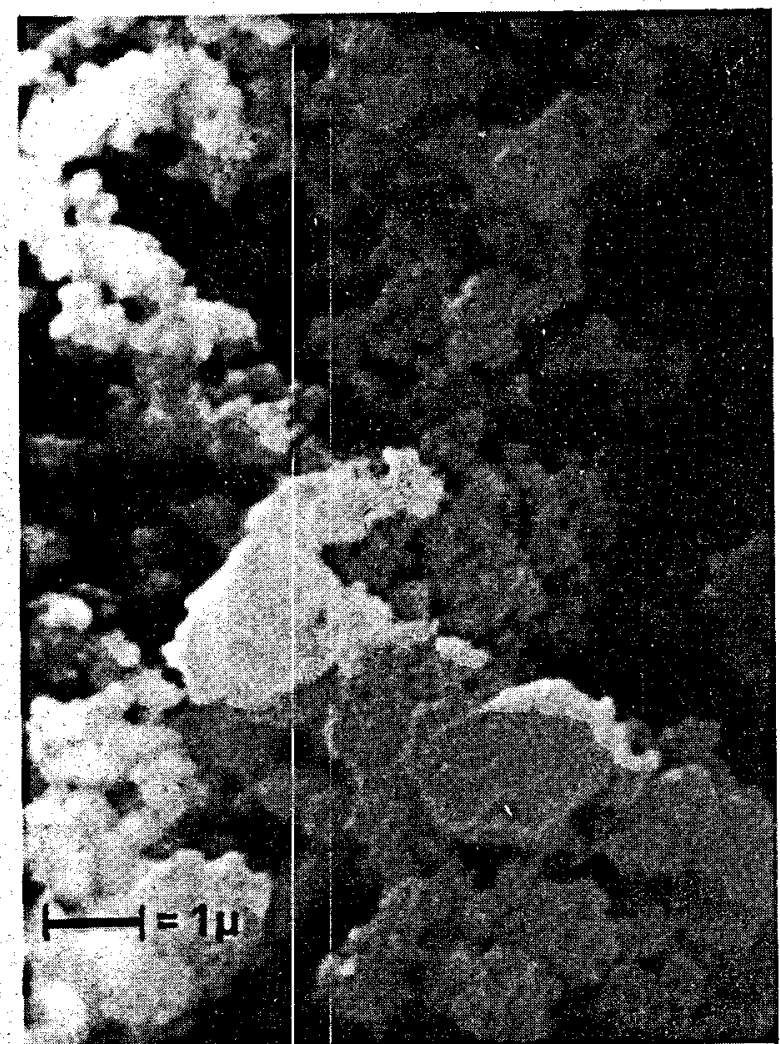

(a)

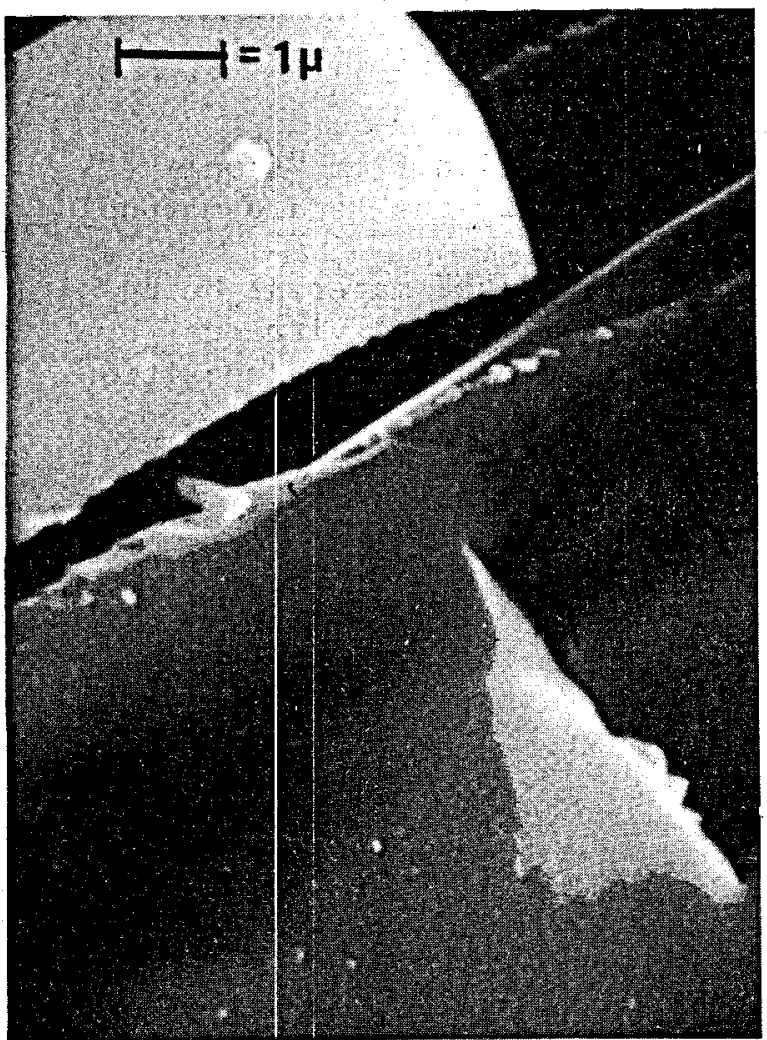

XBB $801-690$

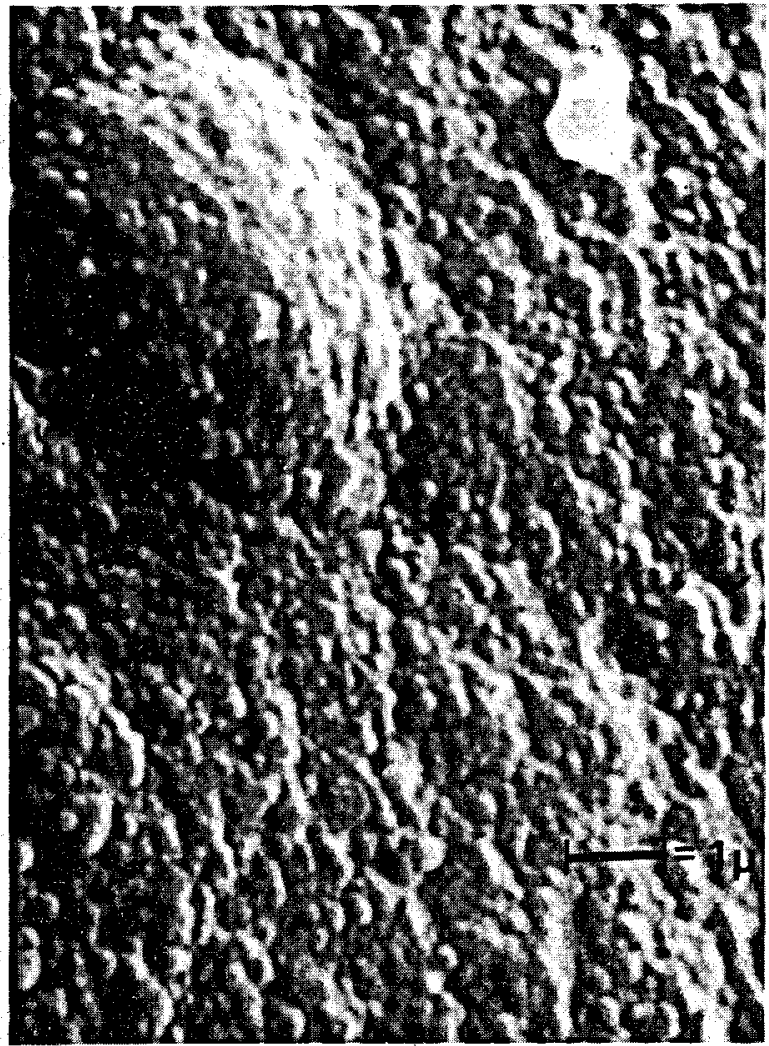

(b)

XBB 801-689

(a) Light, porous white powder.

(b) Stratified, medium density, solid deposit; "typical" silica scale.

(c) Transluscent glass-like material.

A11 three photos are $10,000 \mathrm{x}$ scanning electron micrographs. 
Figure 15

"Vitrified Scale" from a Low Pressure Brine Discharge Line

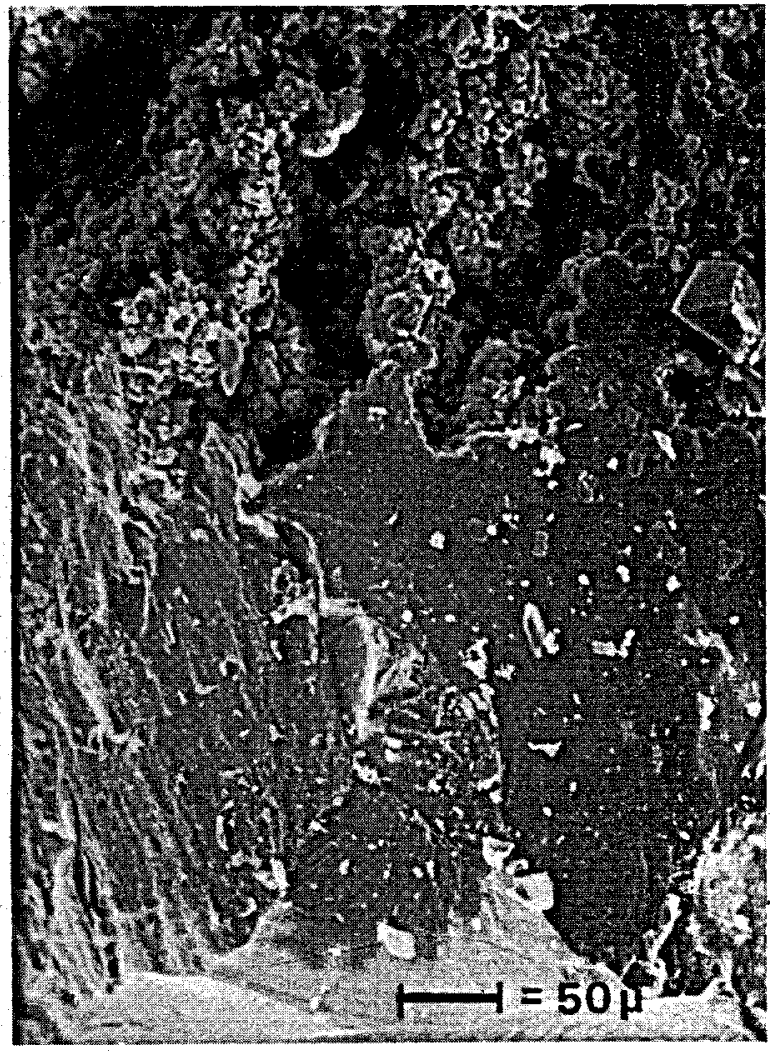

(a)

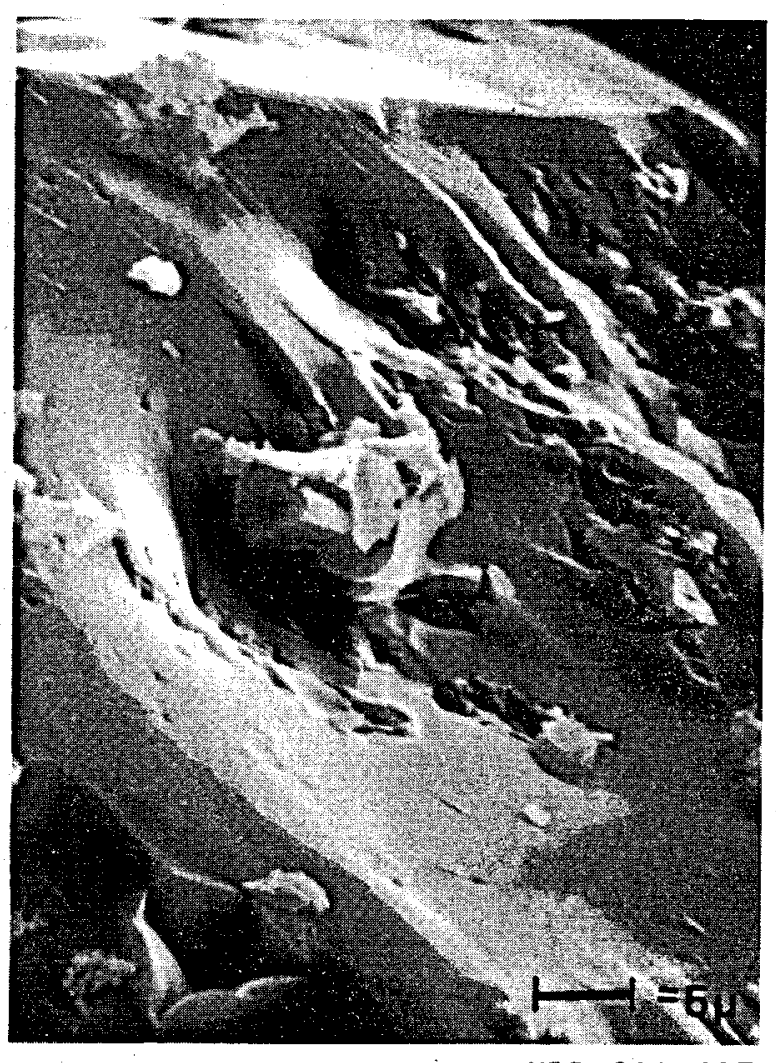

XBB 801-687

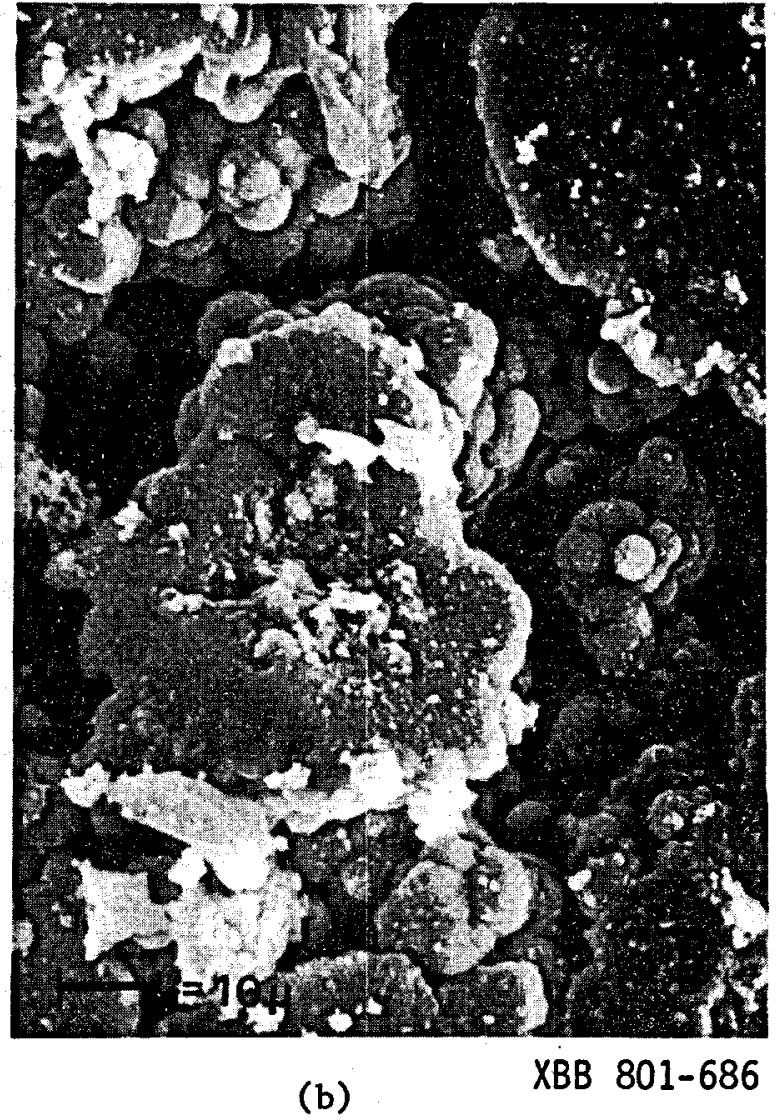

(a) Transition from "floclike"
to "vitreous" scale morphology.

(b) "Floclike" material being converted to "vitreous" by dissolved silica deposition.

(c) "Vitreous" material with residual cavities.

(c) 
on a macroscopic scale, this specimen shows obvious ripple-like "depositional structures" that could only have been formed by hydrodynamically controlled deposition of colloidal particles or clumps.

Figure 15 also illustrates the progression from floc-11ke to glass-11ke deposits. All three pictures are of the same specimen, but taken at different magnifications. Macroscopically, the sample is a light, porous, but locally vitreous looking inhomogeneous black material. It was collected from the brine discharge line of a low pressure steam separator, near the separator. The specimen consists mostly of $\mathrm{SiO}_{2}$, but parts of it also contain significant concentrations of iron and other elements (determined by electron dispersion spectroscopy).

Figure 15 (a) shows both "floclike" and "vitreous" areas and the transition between them. Figure 15 (b) is a closeup of a "floclike" area which was gradually being "filled In" by molecular deposition of dissolved silica on what appears originally to have been a floclike materlal like that in Figure 14 (a). Figure 15 (c) shows a "vitreous" area which is glasslike except for some residual cavities.

Figure 16 shows typical "synthetic scale" samples produced in the experiments discussed In Sections 8 and 9. Figures 16 (b) and 16 (d) show the same specimen which was taken from the last (downstream) tube segment used in an experiment at $\mathrm{pH} 7.35$. Figure 16 (a) shows scale deposited in the first (upstream) tube segment in the same experiment. Figure 16 (c) shows scale deposited in the first tube segment used in an experiment at $\mathrm{pH}$. 6.95. (Scale samples produced at different $\mathrm{pH}$ values may be compared because it was found that brine $\mathrm{pH}$ has $11 \mathrm{ttle}$ effect on scale morphology in the range studled.)

Figures 16 (a) and (b) show that, although the synthetic scale is solid, its microscopic structure resembles that of the powdery material shown in Figure 14 (a); $1 . e .$, the synthetic scale is only very weakly cemented. Apparently, longer times are required to form the well cemented structures shown In Figures 14 (b) and (c) and Figure 15. The two low magnification Figures 16 (c) and (d) show the grossly inhomogeneous macroscoplc appearance of the synthetic scale. In the upstream segment shown In Figure 16 (c), the inhomogenelty takes the form of "patchy" covering of the tube wall. In the downstream segment shown in Figure 16 (d), much of the deposited silica actually 
Figure 16

"Synthetic" Silica Scale

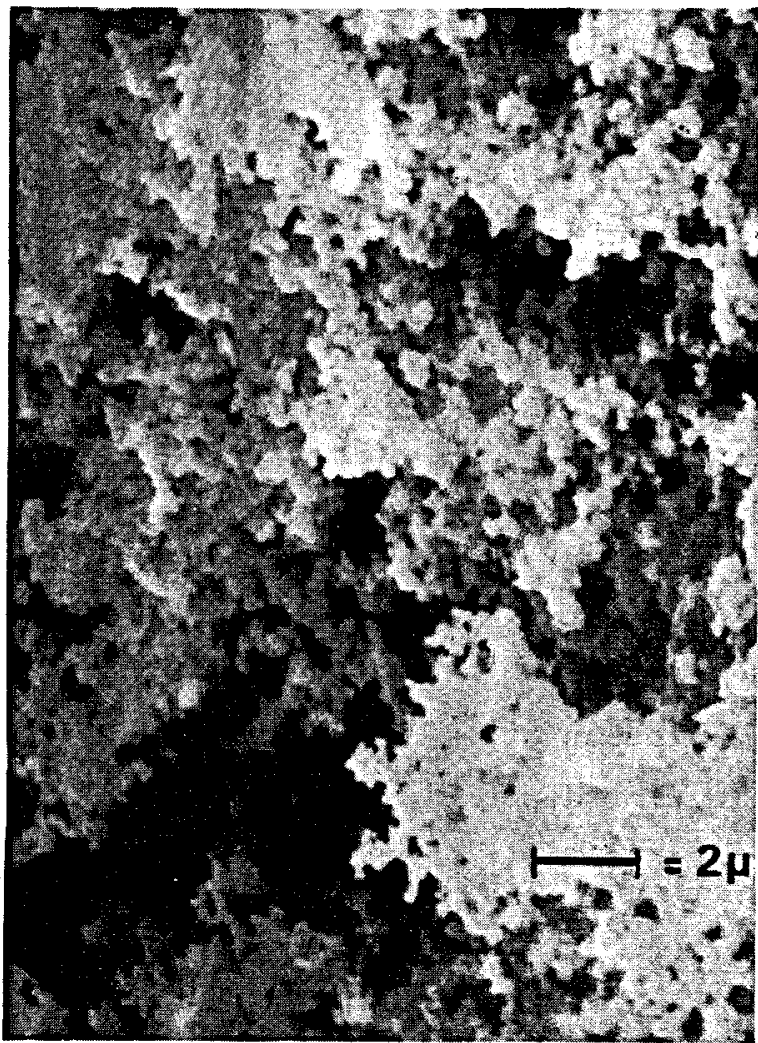

XBB 801-691

(a) Scale from first (upstream) tube segment, $\mathrm{pH} 7.35$.

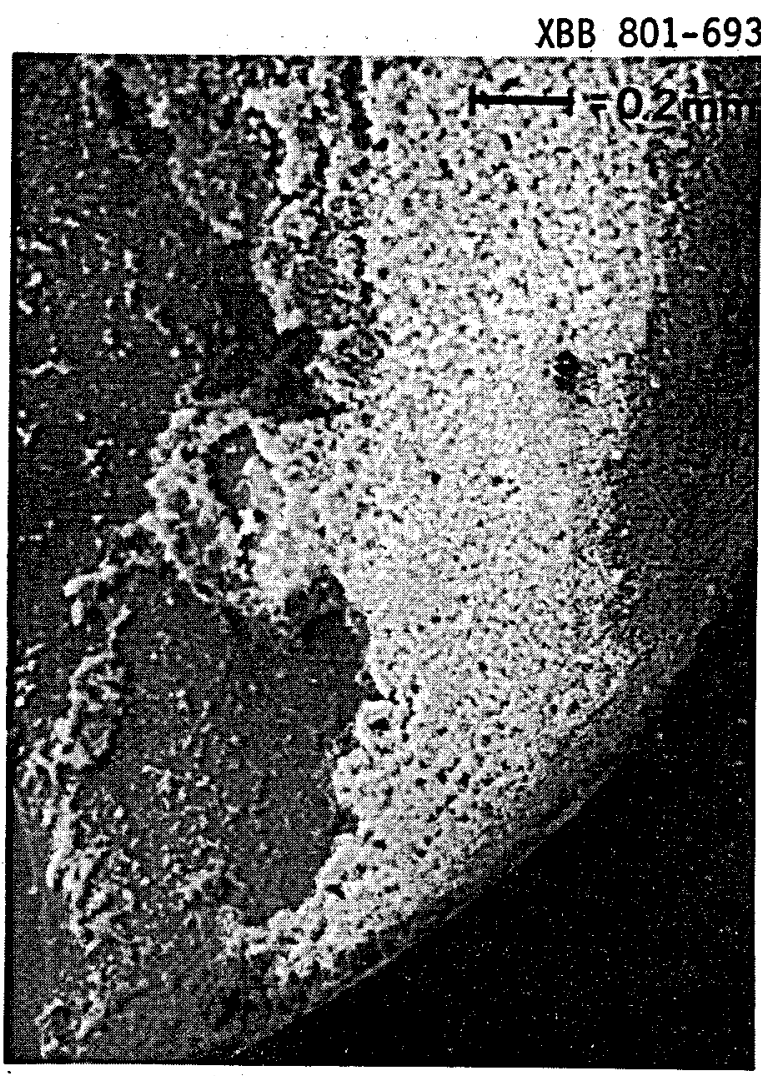

(c) First tubè segment, $\mathrm{pH}$ 6.95.

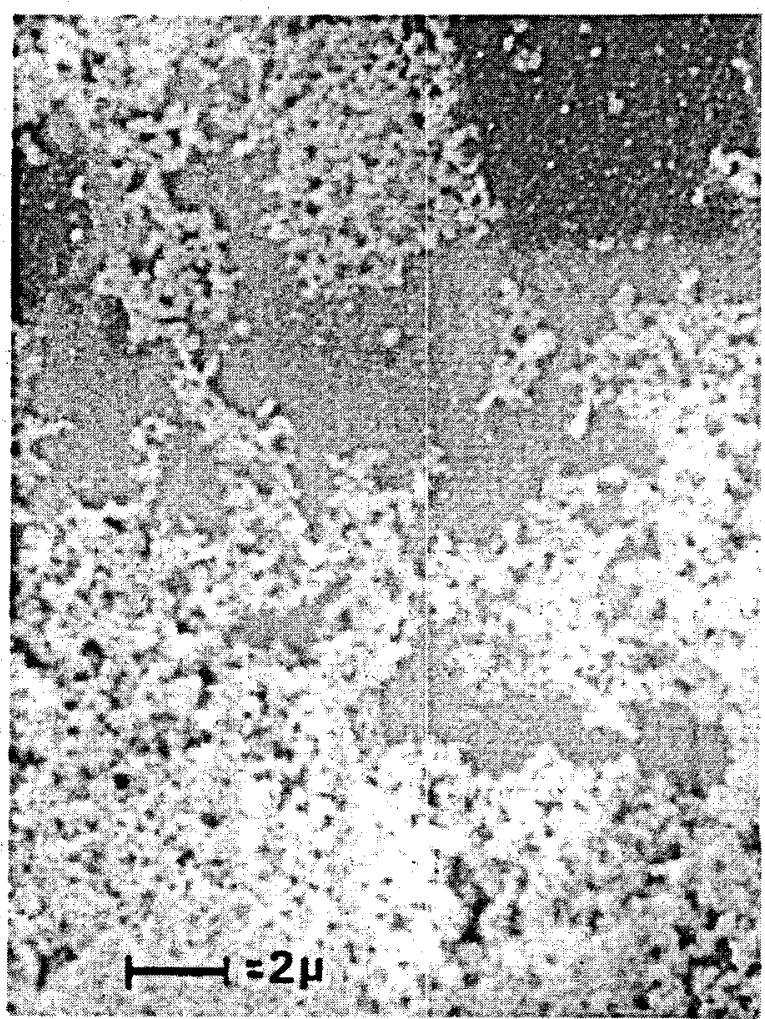

XBB 801-692

(b) Last (downstream) tube segment. Same experiment as: (a).

XBB 801-694

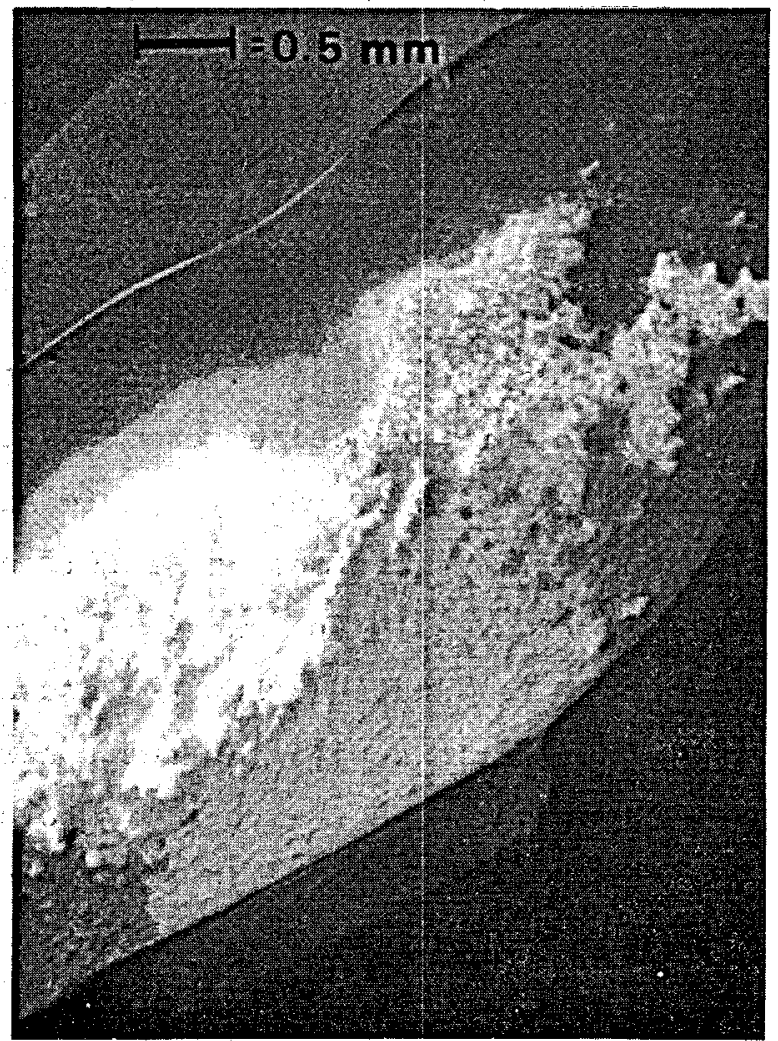

(d) Same specimen as (b). 
settled on the bottom of the tube. (This is commonly visible to the naked eye In the downstream tube segments.) The weaker cementation of the material in Figure 16 (d) is demonstrated by the "glow" in the Image, which is caused by the inability of sputtered gold to render a very poorly consolidated specimen conductive enough to prevent charge bulldup. It is striking how little the appearance of these specimens varles with magnification.

\section{S11 The Equilibrium Chemistry of Cerro Prieto Brines}

As was previously discussed, adding lime to increase brine $\mathrm{pH}$ appears to be a promising method for removing suspended silica from the brine prior to reinjection. However, increasing the $\mathrm{pH}$ carries the risk of causing the precipitation of carbonate minerals. Using sulfuric acid to decrease the brine $\mathrm{pH}$ to reduce silica scaling in the low pressure steam separators carries the risk of inducing the precipitation of sulfate minerals.

To evaluate these possibilities we studied the acid-base chemistry of Cerro Prieto brine and the solubility of carbonate and sulfate minerals in 1t. We used a computer program that calculates the equilibrium chemical properties of a brine of given chemical composition and enthalpy at a given pressure. It resembles other such programs closely. It is called HITEQ, and Is an adaptation of another program that was originally developed by 0 . Weres to model the chemistry of geothermal power plant condensate.

- The basic assumption is that of full thermodynamic and chemical equilibrium in and between the liquid and gas phases. (HITEQ does not model the precipitation and dissolution of solid phases.) Depending on the enthalpy and chemical composition of the system and the pressure specified, the system may consist of a liquid phase only, a vapor phase only, or both. In a typical two-phase situation the liquid phase contalns dissolved gases as well as non-volatile components, and the vapor phase is a mixture of steam and other gases. The 1iquid-phase dissociation and complexing reactions, and the common logarithms of their equilibrium constants, included in HITEQ are listed in Table 6. The partition of gases between the 11quid and vapor phases is calculated using Henry's Law (Table 7). The mineral phases in sILNUC, and the common logarithms of their solubility products at $100^{\circ} \mathrm{C}$, are 11sted in Table 8 . 
Table 6

Solution Phase Equilibria in HITEQ

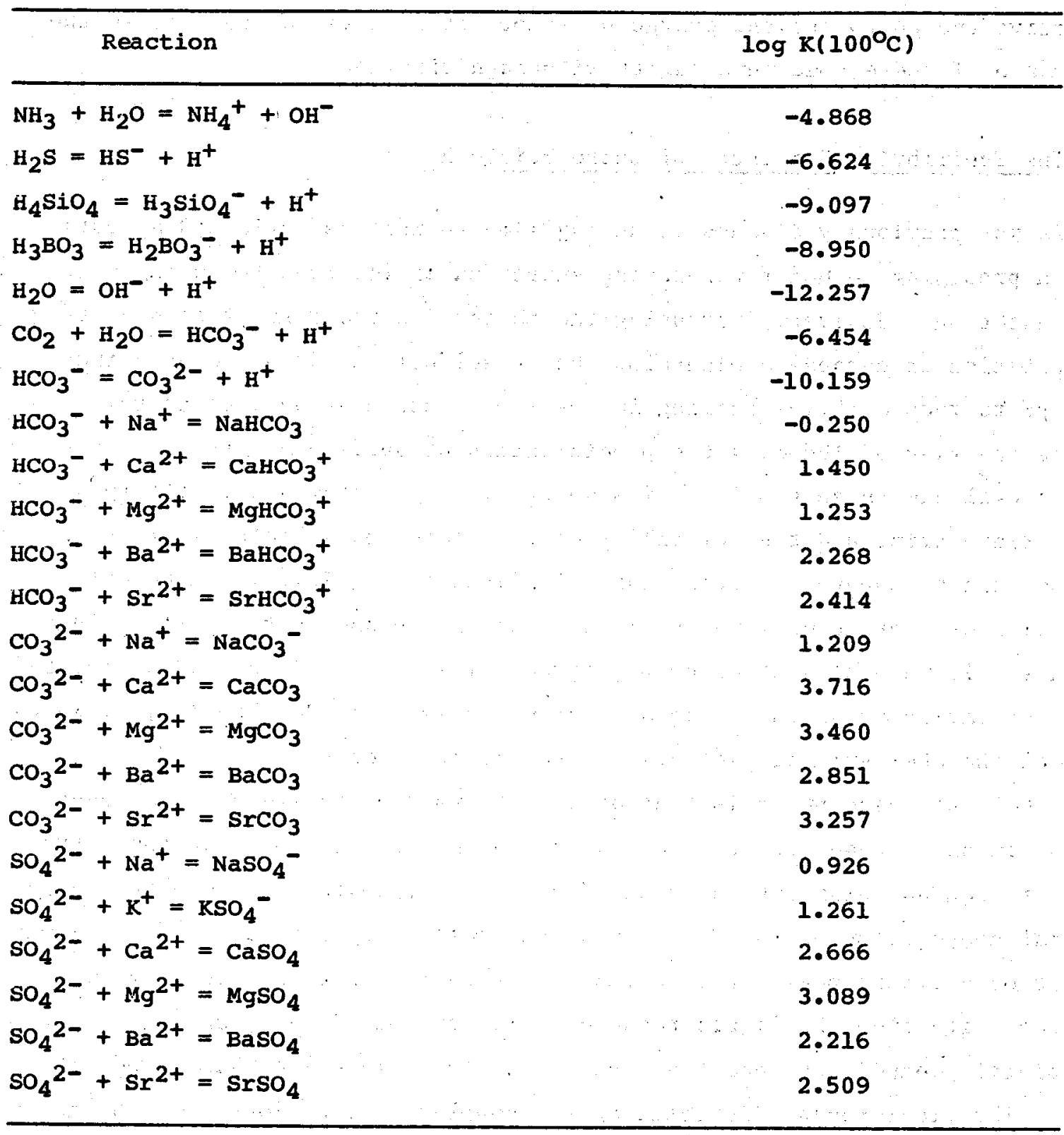

$\mathrm{H}_{2} \mathrm{SO}_{4}, \mathrm{HCl}, \mathrm{NaOH}, \mathrm{KOH}, \mathrm{Ca}(\mathrm{OH})_{2}, \mathrm{Mg}(\mathrm{OH})_{2}$, etc., are assumed to be completely dissociated. 
Table 7

Gas - IIquid Equilibria in HITEQ

\begin{tabular}{l}
\hline \\
\hline $\mathrm{CO}_{2}(\mathrm{aq})=\mathrm{CO}_{2}(g)$ \\
$\mathrm{NH}_{3}(\mathrm{aq})=\mathrm{NH}_{3}(g)$ \\
$\mathrm{H}_{2} \mathrm{~S}(\mathrm{aq})=\mathrm{H}_{2} \mathrm{~S}(\mathrm{~g})$ \\
$\mathrm{N}_{2}(\mathrm{aq})=\mathrm{N}_{2}(g)$ \\
$\mathrm{O}_{2}(\mathrm{aq})=\mathrm{O}_{2}(g)$ at $100^{\circ} \mathrm{C}$ \\
* Henry's Law Constant in units of bars molal -1.276 \\
\end{tabular}

Table 8

Mineral Phases in HITEQ

\begin{tabular}{lll}
\hline $\begin{array}{c}\text { Mineral } \\
\text { name }\end{array}$ & $\begin{array}{c}\text { Chemical } \\
\text { Composition }\end{array}$ & log $\mathrm{K}_{\text {sp }}$ at $100^{\circ} \mathrm{C}$ \\
\hline Calcite & $\mathrm{CaCO}_{3}$ & -9.495 \\
Aragonite & $\mathrm{CaCO}_{3}$ & -9.334 \\
Strontianite & $\mathrm{SrCO}_{3}$ & -11.973 \\
Witherite & $\mathrm{BaCO}_{3}$ & -12.845 \\
& & \\
Anhydrite & $\mathrm{CaSO}_{4}$ & -5.165 \\
Gypsum & $\mathrm{CaSO}_{4} \mathbf{2 H}_{2} \mathrm{O}$ & -5.106 \\
Celestite & $\mathrm{SrSO}_{4}$ & -6.936 \\
Barite & $\mathrm{BaSO}_{4}$ & -9.238 \\
& & \\
\hline
\end{tabular}

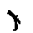


The partial pressure of steam in the vapor phase is taken to be the saturation pressure of water at the calculated temperature. (The thermodynamic properties of pure water are used in HITEQ. This is an approximation, but an acceptable one at the moderate salinity of Cerro Prieto brine,) Ion activity coefficients are calculated using a simple version of the extended Debye-Hückel Theory. The data base covers the range $0-300^{\circ} \mathrm{C}$.

HITEQ's output includes: the temperature, the specific enthalpies and mass fractions of liquid and vapor, the partial pressures of steam and other gases in the vapor phase, the concentrations of the various gases, ions, and complexes in the liquid phase, $\mathrm{pH}$, ionic strength, and the saturation ratios of the carbonates and sulfates of calcium, strontium, and barium.

HITEQ and the chemical model that is embodied in it will be described in detail elsewhere (Iglesias and weres, report in preparation).

First we used HITEQ to compute the chenical equilibrium state of a representative Cerro Prieto brine (Table 9). (This brine corresponds to the "Low Ca" brine of Table 1.) The pH of the "unmodified" brine was taken to be 7.35 . starting out with this "unmodified brine", we either increased the pH by adding lime $\left(\mathrm{Ca}(\mathrm{OH})_{2}\right.$ ) or decreased it by adding $\mathrm{H}_{2} \mathrm{SO}_{4}$ - (In these calculations, the concentration of dissolved $\mathrm{SiO}_{2}$ was assumed to have been reduced to 500 ppm by its conversion to colloidal silica.) The calculated saturation ratios for the six important minerals as a function of $\mathrm{pH}$ are presented in Figure 17. (The saturation ratios for aragonite and gypsum are not shown here or in the following Figures, because they always lie just below the saturation ratios for calcite and anhydrite, respectively.)

The results in Figure 17 indicate that the "unmodified" brine is already supersaturated relative to the three carbonate minerals. However, carbonate precipitation from the flashed brine at Cerro Prieto has not been reported. Either the precipitation of the carbonate minerals is hindered by kinetic factors, etc., or the theoretical predictions of HITEQ are incorrect for some reason. This discrepancy between theory and empirical observation should be cleared up. In the meantime, these theoretically calculated mineral saturation ratios must be used with due caution. 
TABLE 9

"Typlcal Cerro Prieto Brine" Composition

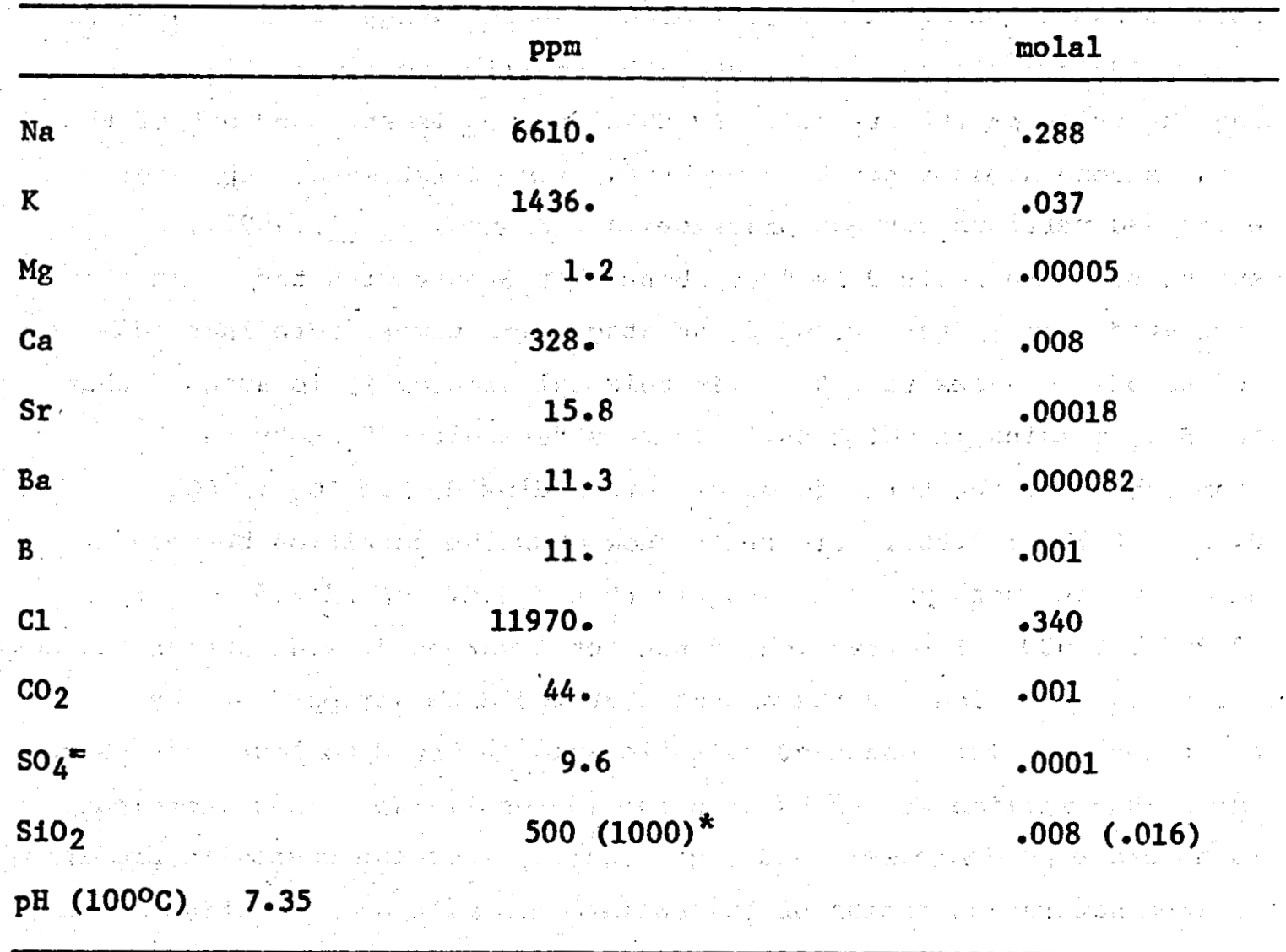

* The total amount of $\mathrm{SIO}_{2}$ initially present in the brine is about 1000 ppm. However, only that portion of it that is actually in solution (as opposed to colloldal silica in suspension) plays a role in the acid-base chemistry of the brine. The dissolved silica concentration rapidly drops to about $500 \mathrm{ppm}$ after the brine has been flashed down to 1 bar and $100^{\circ} \mathrm{C}$. 
In any case, if the practical need were to arise, the high saturation ratios of the carbonates could be decreased by decreasing the concentrations of bicarbonate and carbonate in the brine. This could be accomplished by adding acid to the brine between the first and second stage steam separators (Figure 18). Adding acid shifts the $\mathrm{HCO}_{3}-\mathrm{CO}_{2}$ equilibrium toward $\mathrm{CO}_{2}$ by decreasing the brine $\mathrm{pH}$ (Figure 19), and then the $\mathrm{CO}_{2}$ is stripped out of the brine by the second steam separation process. (The first steam separator pressure assumed reflects current practice; see Alonso, et al.,1979.)

When the brine in Table 9 is "recombined" at 6 bars with the steam that it was separated from in the second flash stage, its temperature increases to $159^{\circ} \mathrm{C}$ and its $\mathrm{pH}$ decreases to 7.02. (In this calculation it is assumed that all of the $\mathrm{SiO}_{2}$ remains in solution.) In this "unmodified" state the equilibrium ratios of the three forms of carbon dioxide are $\mathrm{CO}_{2}: \mathrm{HCO}_{\overline{3}}$ : $\mathrm{CO}_{\overline{3}}:: 0.220: 0.773: 0.007$. Figure 19 shows how the partition between $\mathrm{HCO}_{3}{ }^{-}$and $\mathrm{CO}_{2}$ varies with $\mathrm{pH}$ when $\mathrm{H}_{2} \mathrm{SO}_{4}$ is then added. At $\mathrm{pH}=5, \mathrm{CO}_{2}$ : $\mathrm{HCO}_{3}^{-}:: 0.961: 0.039$. The fraction of the total carbon dioxide present as $\mathrm{CO}_{2}$ in this state is approximately the amount that would be stripped off by subsequent flashing. The amount of sulfuric acid required to lower the pH to this value is 0.6 millimoles per $\mathrm{kg}$ of brine $(60 \mathrm{ppm})$. We do not anticipate that this moderate $\mathrm{pH}$ decrease would significantly increase corrosion problems. The calculated saturation ratios of the sulfate minerals as a function of $\mathrm{pH}$ when sulfuric acid is added at this temperature are presented in Figure 20. It appears that the solubility of barite may limit the use of inexpensive $\mathrm{H}_{2} \mathrm{SO}_{4}$ for this purpose.

Taking brine acidified to $\mathrm{pH} 5$ with $\mathrm{H}_{2} \mathrm{SO}_{4}$ at $159^{\circ} \mathrm{C}$ and flashing it we find that the $\mathrm{pH}$ at 1 bar is 6.34 and that the total amount of carbon dioxide and bicarbonate remaining in the liquid phase is reduced to $3 \times 10^{-3}$ mmole/kg. The effect of then adding lime to increase the brine pH upon the mineral saturation ratios is shown in Figure 21 . We see that supersaturation with the carbonate minerals has been avoided. However, the brine is supersaturated with barite. This may be avoided by replacing all or part of the sulfuric acid with hydrochloric acid, but at increased chemical cost. The amount of $\mathrm{Ca}(\mathrm{OH})_{2}$ needed to increase the $\mathrm{pH}$ of the separated brine to about 7.8 , as required to flocculate the silica, was found to be about $0.5 \mathrm{mmole} / \mathrm{kg}$, which corresponds to $28 \mathrm{ppm}$ CaO. (In this part of the calculation the concentration of $\mathrm{SiO}_{2}$ in the brine was again assumed to be $500 \mathrm{ppm.}$ ) 
Saturation ratio vs. $\mathrm{pH}$ for a typical separated Cerro Prieto brine

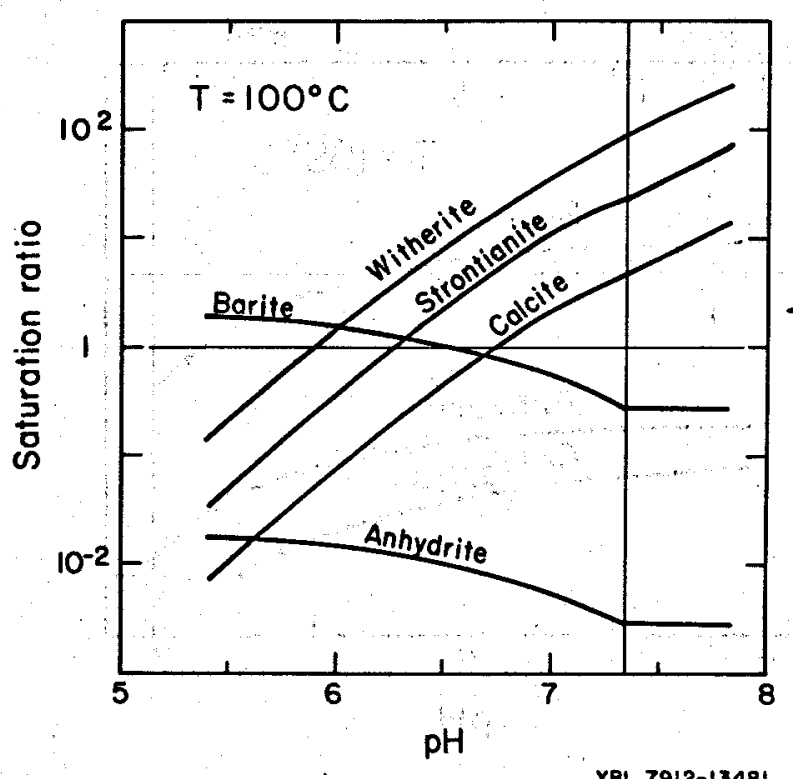

F1g. 17. The vertical line Indicates the pH of the "unmodified" brine. $\mathrm{pH}$ is increased by adding lime, and decreased by adding sulfuric acid.
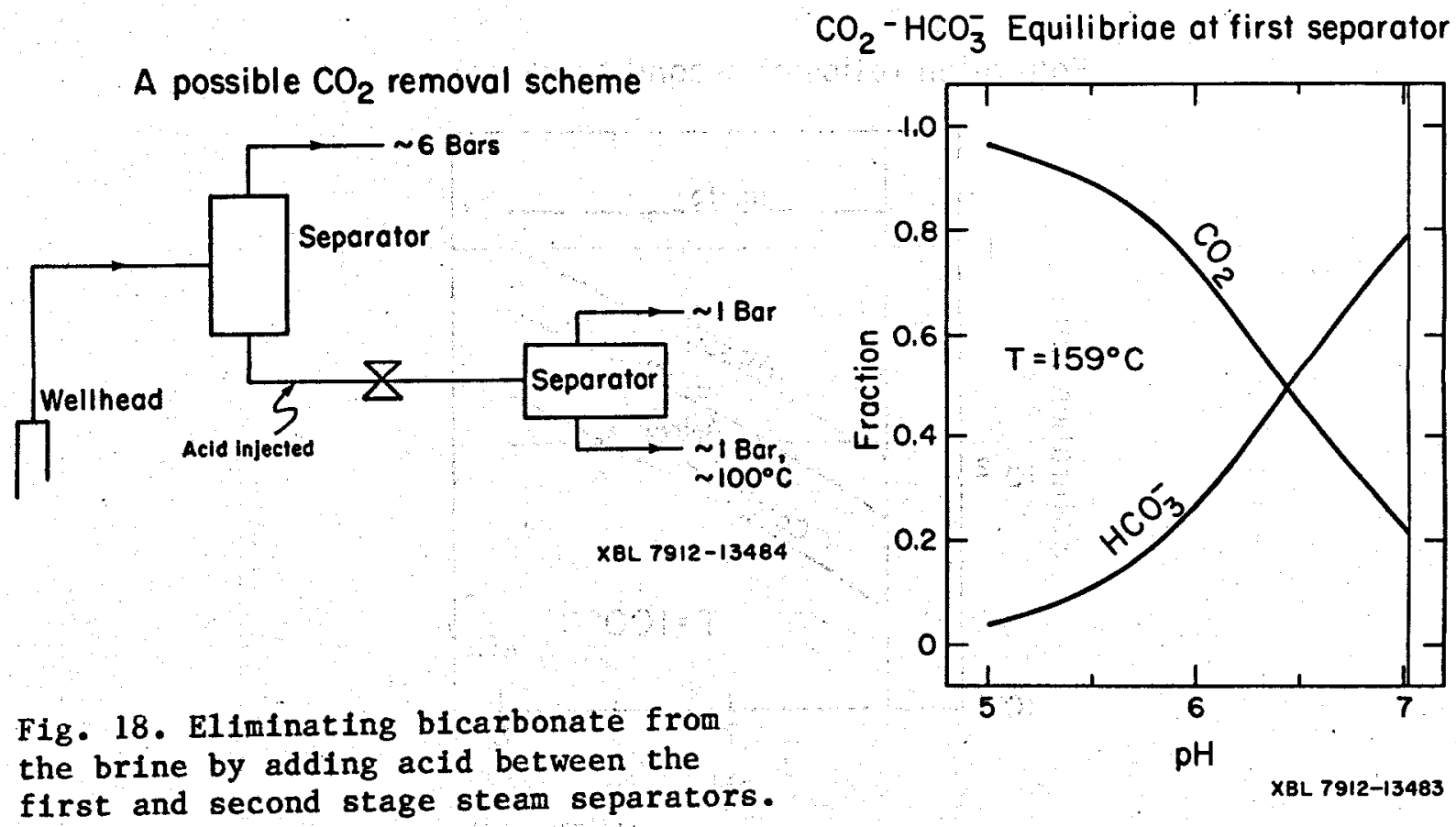

Fig. 19. Effect of adding acid to brine exiting the first steam separator. Vertical line indicates $\mathrm{pH}$ of unmodified brine. 
Saturation ratios at first separator

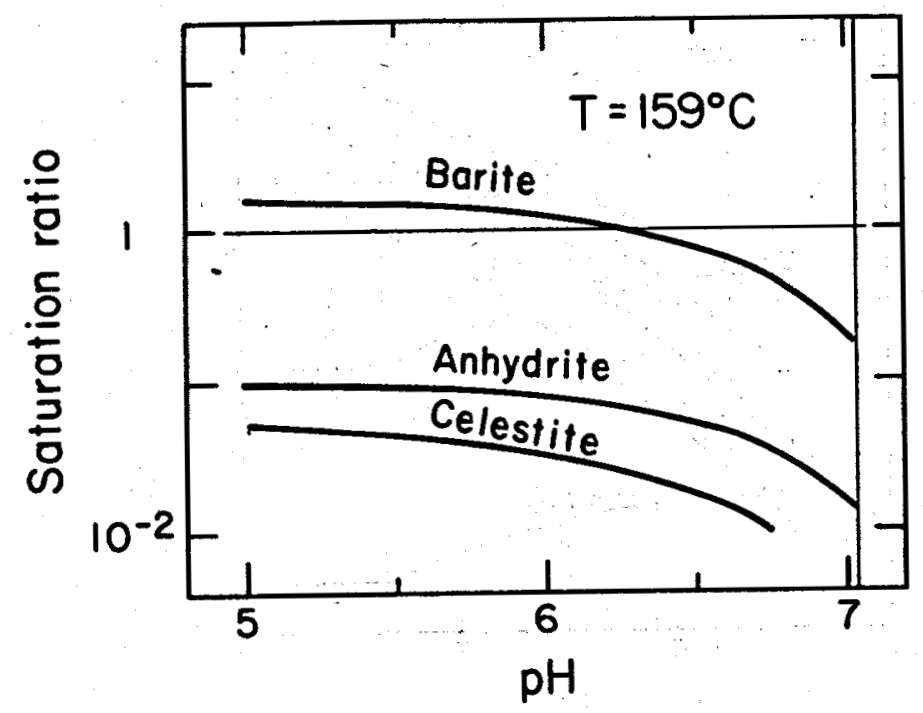

XBL $7912-13480$

Fig. 20. Effects of adding sulfuric acid on the saturation ratios of the sulfate minerals.

Saturation ratios at second separator

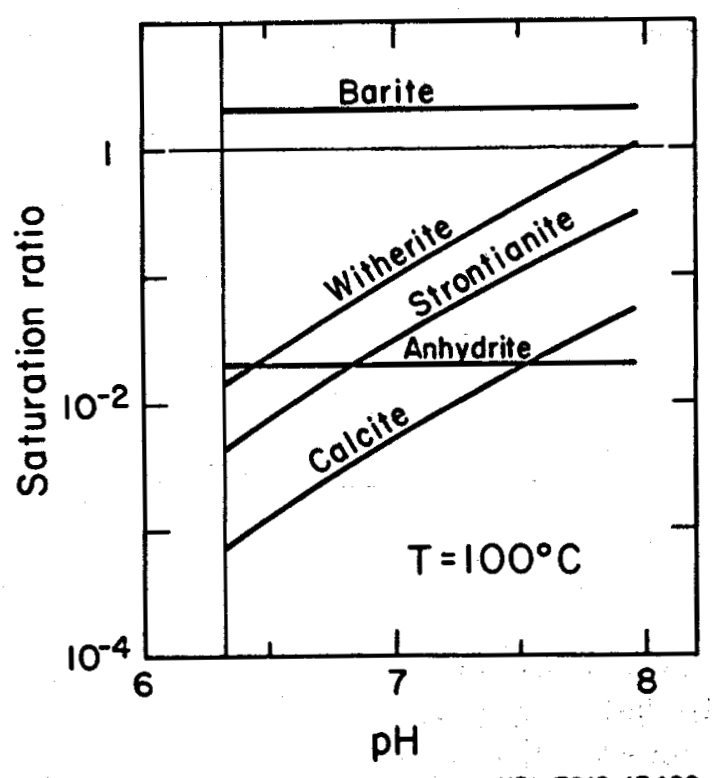

Fig. 21. Effects of then adding lime to the flashed brine at atmospheric pressure. Vertical line indicates the $\mathrm{pH}$ of the brine at $100^{\circ} \mathrm{C}$ after its $\mathrm{pH}$ has been lowered to 5 at $159^{\circ} \mathrm{C}$. 
If both acid and lime are to be used, the lime should be added to the brine in two doses. First, enough lime should be added to the brine before it enters the aging tank to increase its pH to about 7.1. This would cause rapid polymerization, but would avoid premature flocculation in the aging tank. The rest of the lime needed to increase brine pH to about 7.8 would then be added to the mixing tank between the aging tank and the clarifier as before.

Assuming that $20 \mathrm{~kg}$ of separated brine is to be treated per $\mathrm{kWh}$ generated, we estimate that the amount of $\mathrm{H}_{2} \mathrm{SO}_{4}$ needed would cost about $2.0 \times 10^{-5}$ US\$ $\mathrm{kWh}^{-1}$; the cost of an equivalent amount of $\mathrm{HCl}$ would be $2.17 \times 10^{-4}$ US\$ $\mathrm{kWh}^{-1}$. The cost of the lime would be $2.0 \times 10^{-5} \mathrm{uss} \mathrm{kWh}^{-1}$, in either case. These estimates are based on typical us West coast bulk chemical prices quoted in the Chemical Marketing Reporter of January 21, 1980. The prices assumed were: US\$ 15 ton $^{-1}$ for smelter grade $1008 \mathrm{H}_{2} \mathrm{SO}_{4}$ in tankcars; US\$ 62.50 ton $^{-1}$ for $18^{\circ}$ Baume $\mathrm{HCl}(298$ by weight $\mathrm{HCl})$ in tanks; and US\$ 32.50 $\mathrm{ton}^{-1}$ for quicklime (CaO) in pebble form, in 25-ton lots. These are prices "at the works." The cost of shipment to Cerro Prieto would increase them somewhat. (US tons assumed throughout this paragraph.)

These calculations suggest that the proposed scheme for preinjection brine treatment at Cerro Prieto is both technically and economically feasible. If increasing the pH does indeed cause precipitation of carbonates, this problem may be eliminated at reasonable cost by adding acid. Adding acid in the amount and place appropriate to this purpose would also reduce the rate of silica scaling in the low pressure steam separators and associated piping by fourfold or better (see section 9 above).

These conclusions must, of course, be tested in the field by means of appropriate pilot scale experiments.

\section{$\$ 12$ Conclusions}

It has been demonstrated that the chemistry of silica in Cerro Prieto brine may profitably be studied in the laboratory using synthetic brines. Because some properties of the brine vary greatly with its composition,.. . such results must be confirmed in the field using actual brines. However, the results of the synthetic brine work are good enough to allow practical 
brine treatment processes to be proposed based on them, and to contribute to the planning of a well defined program of pilot plant studies.

The same techniques could be applied to the study of silica chemistry in other silica rich geothermal brines that precipitate relatively pure amorphous silica. These include the brines at Wairakel and Broadlands (New Zealand), Los Azufres (Mexico), and Baca site (USA).

The detailed conclusions and recommendations in this report are specific to Cerro Prieto. Experience has shown that even the variation between individual wells in one field can be great enough to make a treatment that works with brine from one well not work with that from another. The difference between different fields is so large that, for all practical purposes, the problems at each field must be addressed separately. of course, this is not to say that the experience gained and inethodology developed in one. place cannot be transferred to another.

our limited effort to study the precipitation of calcium carbonate from synthetic Cerro Prieto brine was unsuccessful. (See Appendix 2). This is a trickier experimental challenge because of the volatile nature of carbon dioxide and because heterogeneous nucleation is probably important in the case of carbonates. However, properly designed and carefully executed experiments with synthetic brines should be able to address this problem as well. The same consideration applies to the other carbonates and sulfates.

our attempts to theoretically model the equilibrium chemistry of Cerro Prieto brines produced mixed results. Our calculations indicate that unmodified flashed Cerro Prieto brine is supersaturated with calcite and other carbonate minerals, but precipitation of carbonates in the wastewater system at Cerro Prieto has not been reported. Overall, we feel that the only immediately useful results to be expected from such calculations at this time are theoretically calculated titration curves. These are indeed useful for predicting the cost of modifying the $\mathrm{pH}$ of the brine. Calculated mineral solubilities and saturation ratios can only be considered to express "the potential for precipitation".

Aside from the usual problems of bad and/or incomplete data, we believe that the uncertain quality of such theoretical predictions is in large measure due to the inadequate and inconsistent theories of strong, mixed el ectrolyte solutions now in common use. Each author uses his own version 
of these theories to fit his experimental data or perform his calculations. Because of this, the data in the various data bases is simply inconsistent. The worst part of all this is the introduction of numerous "ion pairs", which may or may not actually exist, into these models to compensate for the basic inadequacy of the electrolyte theory employed. The values for the formation constants of these "ion pairs" that are "determined" or "derived" or just assigned by various authors sometimes differ by orders of magnitude. Pitzer's (1973) powerful new theory appears to be a promising alternative to all this. This theory is able to accurately fit the properties of strong electro lyte solutions with few parameters and without recourse to "ion pairs".

In this area of geothermal chemistry as in others, there is a great need for careful comparison and reconciliation of theoretical predictions, laboratory data, and field observations.

\section{Acknowledgements}

This work was supported by the Division of Geothermal Energy of the United States Department of Energy. It was part of the Cerro Prieto Research Project in this Laboratory, and fell under the auspices of the DOE/CFE cooperative agreement.

The authors wish to acknowledge the extensive help rendered to then by the chemical researchers at CFE - A. Mañon M., J. Fausto L. and F. Garibaldi - and at IIE - R. Hurtado J. and S. Mercado. R. L. Fulton and E. Eno worked with us on the design of a pilot plant that was ultimately not built by us. Their assistance and encouragement are duly acknowledged.

Other persons who contributed assistance, information, advice, or encouragement to this work include J.A. Apps, R.A. Gray, S.M. Klainer, D.L. Lessor, M.J. Lippmann, L.L. Mink, F. Pearson, M.R. Reed, H.P. Rothbaum, W.H. Somerton, J.F. Thomas, A.H. Truesdell, D. White and A. Yee. P.A. Butler typed this manuscript, and C. Carnahan and M.J. Lippmann reviewed it. 



\section{Appendix 1 Continuous Silica Recharge Experiment}

It is of considerable practical interest to study the interaction of dissolved silica with pre-existing flocculated colloidal silica, as in a reactor clarifter. We developed an experimental method suitable for this purpose and believe that it produces valid results. However, we did not have the opportunity to properly verify these results or to work with the technique enough to fully appreciate its possibilities and limitations.

It would not be practical to accumulate flocculated silica from a large volume of flowing synthetic brine, as actually happens in a reactorclarifier. Instead, we prepared a small volume of synthetic brine in a beaker and gradually added concentrated "silica recharge solution" to it (using a peristaltic pump) without otherwise changing its composition.

The experiment was initially set up just like a silica removal experiment of the kind discussed in Sections 3 to 5. The synthetic brine used was formulated to resemble the High $\mathrm{Ca}$ synthetic brine of Table 1, except that the barbital concentration in tt was five times higher $(0.1 \mathrm{M}$ instead of $0.02 \mathrm{M})$.

A $0.2-L$ volume of this synthetic brine containing $1.0 \mathrm{~g} \mathrm{~L}^{-1}$ dissolved $\mathrm{SHO}_{2}$ was constituted in the usual way and its $\mathrm{pH}$ measured. It was then allowed to sit undisturbed for ten minutes to let the dissolved silica concentration drop to a nearly steady state value. Then "silica recharge" was initiated by turning on the peristaltic pump. Two streams - one acid and one basic - were continuously added to the brine from then on with rapid stirring. The basic stream consisted of a sodium metasilicate solution that contained $10.2 \mathrm{~g} \mathrm{~L}^{-1}$ dissolved $\mathrm{SiO}_{2}$. The acid stream contained sufficient HCl to neutralize the basic stream $(0.34 \mathrm{M})$, the chlorides of sodium, potassium, and calclum, and boric acid. The salt concentrations were double those in the synthetic brine. The high concentration of barbital put into the synthetic brine at the beginning was needed to keep the inevitable slight mismatch between the two recharge streams from seriousiy perturbing the $\mathrm{pH}$.

The net effect of running the two recharge streams into the synthetic brine was to add to the beaker a small amount of neutral brine whose salt content was identical to that of the brine already in the beaker, but which 
contalned a much higher dissolved silica concentration and no barbital. In a mass balance sense, this is actually equivalent to what goes on in a reactorclarifer. The only difference is that here much less water and salt are added, and no clarifled brine "overflows."

At ten-minute intervals the pump was stopped, the time recorded, and the floc allowed to settle brlefly. Then a sample of supernatant brine was drawn off with a 1.0-ml syringe for analysis, and the $\mathrm{pH}$ measured. Only MAS was analyzed for. After 100 minutes the experiment was ended and the final reaction volume recorded.

The specific rate of deposition of dissolved silica onto collotdal silica in $g(\mathrm{~g} m)^{-1}$ was determined from the data as follows:

First we calculated as functions of time

$V=$ The volume of solution $=\nabla_{1}+f_{e} t_{r}$

$Q_{t}=$ total amount of silica present $=C_{1} v_{1}+C_{r} f_{r} t_{r}$

$Q_{d}=$ total amount of dissolved silica $=c V=c\left(V_{1}+f_{e} t_{r}\right)$

$Q_{s}=$ solid or colloidal silica $=Q_{t}-Q_{d}$

where

$V_{i}=$ the Initial volume $=200 \mathrm{ml}$,

$f_{r}=$ flow rate of each recharge stream $=0.5 \mathrm{ml} \mathrm{min}-1$

$f_{e}=$ total "effective flow rate," corrected for evaporation losses

$t_{r}=$ cumulative time duration of pumping

$C_{1}=$ initial silica concentration in $V_{1}$.

$\mathrm{C}_{\mathrm{r}}=$ concentration of silica in the basic recharge stream $=0.1692 \mathrm{M}=$ $10.17 \mathrm{~g} \mathrm{~L}^{-1}$

C = empirically determined MAS concentration

Although the total inflow rate was $1.0 \mathrm{ml} \mathrm{min-1,} \mathrm{evaporation} \mathrm{lead} \mathrm{to} \mathrm{a}$ significant loss of volume. After 100 minutes the increase in volume should have been $100 \mathrm{ml}$, but the measured Increase was $70 \mathrm{ml}$. It was assumed that the evaporation occurred at a constant rate. This gave an "effective flow rate" $f_{e}$ of $0.7 \mathrm{ml} \mathrm{min}^{-1}$, and this value was used to calculate $Q_{d}$.

$v, Q_{t}, Q_{d}$, and $Q_{s}$ were calculated for each sample point.

Then

$\mathrm{dQ}_{\mathrm{g}} / \mathrm{dt}=\mathrm{dQ} / \mathrm{dt}-\mathrm{dQ} \mathrm{d} / \mathrm{dt}=\mathbf{f}_{\mathrm{r}} \mathrm{C}_{\mathrm{r}}-\mathrm{dQ} \mathrm{d} / \mathrm{dt}$

$R_{s}=$ the specific reaction rate $=Q_{s}^{-1} d_{s} / d t$

In practice, since only a finite number of concentration measurements 


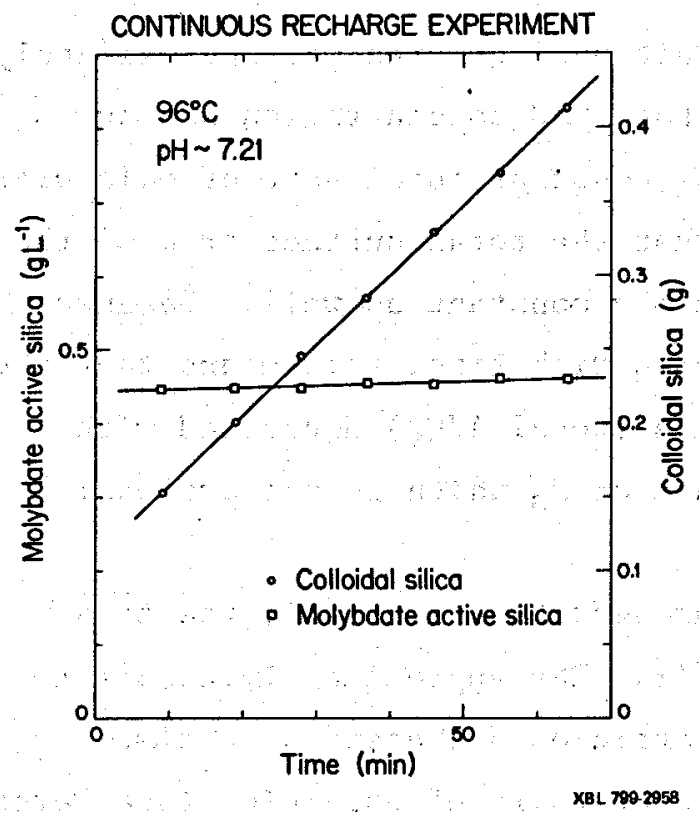

Fig. Al. MAS concentration and total amount of colloidal silica present as a function of time from start of recharge.

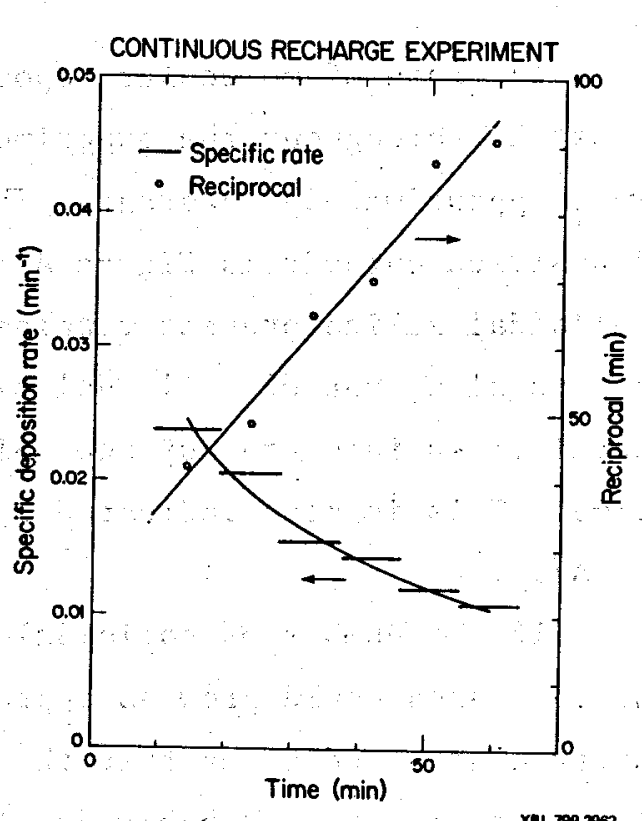

Fig. A2. "Reciprocal" is that of the "Specific Deposition Rate".

were made, ratios of finite differences were used in place of derivatives: $\Delta Q_{g} / \Delta t=\Delta Q_{t} / \Delta t-\Delta Q_{d} / \Delta t=f_{r} C_{r}-\Delta(V C) / \Delta t$

$\mathrm{R}_{\mathrm{S}}=\mathrm{Q}_{\mathrm{g}}^{-1} \Delta \mathrm{Q}_{\mathrm{g}} / \Delta \mathrm{t}$

This calculation was performed for each interval between sample points.

The experimental and calculated results from an experiment of this sort are presented in Figure $A 1$ and $A 2$. The empirical values of $C$ and calculated values of $Q_{s}$ are presented in Figure Al. C remains essentially constant, and $Q_{s}$ Increases IInearly with t1me. In other words, the "recharged" silica was converted to colloldal sillca by molecular deposition on preexisting particles at a constant rate:

The calculated values of $R_{S}$ and its reciprocal are presented in Figure A2. The values of $R_{s}$ are plotted as horizontal bars rather than as points, consistent with the finite difference method used to calculate them. Each point represents a value of the reciprocal of $R_{S}$, and is plotted directly above the midpoint of the bar that represents the corresponding value of $R_{S}$. That these points "oscillate" about a straight line fitted to them is an artifact of the finite difference calculation. 
The rate of molecular deposition per unit surface area was approximately constant throughout the experiment because both MAS concentration and $\mathrm{pH}$ were approximately constant. Therefore, the constant total rate of molecular deposition evident in Figure Al indicates that the total surface area of the colloldal silica present remained approximately constant as well. Because the total amount of colloidal silica increased with time, this means that the specific surface area of the colloidal silica (total $A / Q_{S}$ ) decreased with time. This is also indicated by the decrease of $R_{S}$ which is proportional to $\mathrm{A} / \mathrm{Q}_{\mathrm{S}}$.

If the number of colloidal particles present were constant, the total surface area would grow as approximately $Q_{S}^{2 / 3}$. The approximately constant surface area Indicates that the number of particles decreased with time. This decrease was probably due to the fusion of pairs of particles (see Weres et al., 1980, Section 3.12). No new particles were formed after sillca recharge was initiated because the silica saturation ratio remained too low for homogeneous nucleation to occur.

Introducing the simplifying approximation that all of the particles are spherical and of about the same size, it is easy to show that the number of particles varies as $Q_{S}^{-2}$ and that their average radius is proportional to $Q_{S}$. Also, the radius is proportional to $\left(A / Q_{S}\right)^{-1}$ and, therefore, to $R_{S}^{-1}$. Thus, $R_{s}^{-1}$ should be proportional to $Q_{S}$. Comparing the plots of $Q_{s}$ and $R_{s}^{-1}$ In Figures $A 1$ and $A 2$, we see that this is true within the accuracy of the data; both $Q_{S}$ and $R_{\delta}^{-1}$ vary Iinearly with time, and both increase by about the same factor over 60 minutes.

The practical implication of all this is that sludge recirculation may be ineffective in reducing the dissolved silica concentration in Cerro Prieto brine. The reason is that recirculating the sludge does not appear to increase the surface area that is avallable for the molecular deposition of dissolved silica because the number of colloidal particles is continually being decreased by particle fusion. of course, brine coming into the reactorclarifier would introduce additional particles into the sludge. This does not happen in our experiment. However, these newly nucleated particles may be too small to continue growing at the relatively low dissolved silica concentration in the reactor-clarifier. Only more sophisticated laboratory experiments and/or field tests can resolve this question. 
Appendix 2 Precipitation of Calc1um Carbonate from Synthetic Brine

As noted in Section 11 , freshly flashed Cerro Prieto brine appears to be supersaturated with calcite. This led us to attempt to study the simultaneous precipitation of calcium carbonate and amorphous silica from synthetic brine.

The synthetic brine used in these experiments differed from the High Ca brine in Table 1 only in that it contained 1 mmole $\mathrm{L}^{-1}$ of bicarbonate 1on. This was put into the brine by adding the approprlate amount of sodium carbonate to the sodium metasilicate stock soluton. The additional amount of hydrochloric acid needed to convert the carbonate to bicarbonate was added Into the acid, buffer, and salt mixture.

This synthetic brine was formulated in the usual way and its $\mathrm{pH}$ was increased after about 30 minutes by adding NaOH. The "clarified brine" was separated from the flocculated sllica by decantation, and filtered to collect the solids that remained In suspension in 1t. Both the solids filtered out of the "clarified brine" and the flocculated silica were then analyzed for their calcium content. Only a trace of calcium was detected in either. This small amount probably came from the small amount of synthetic brine that remained with the solids.

This negative result may not have been meaningful. It is quite possible that much of the bicarbonate in the synthetic brine was lost by the escape of carbon dioxide during the experiment. (This would not have significantly changed the brine $\mathrm{pH}$ because of the presence of the buffer.) This problem could be eliminated by running the reaction in a sealed, completely 11quid filled container, but we did not do this.

In any case, the following analytic procedure was employed:

The solids on the filter were washed into a 25-m1 volumetric flask with enough $0.01 \mathrm{~N} \mathrm{HCl}$ from a pipette to fill the flask. This solution was then analyzed for calcium using an atomic absorption spectrometer.

The flocculated sllica was scraped and poured into two plastic centrifuge tubes and then spun down. This was repeated several times unt11 all of the floc in the beaker had been transferred. The final volume of the spun down floc in each tube was about $4 \mathrm{ml}$.

The floc in one tube was washed three times by adding $8 \mathrm{ml}$ of deionized 
water and stirring, then centrifuging, and finally removing the water from above the precipitate using a pipette. Then the floc in each tube was extracted three times with $8 \mathrm{ml}$ of $0.01 \mathrm{M} \mathrm{HCl}$ in a manner like the washing. The extract was placed in $50.0-\mathrm{ml}$ volumetric flasks and made up to volume with defonized water.

The solution in each flask was then analyzed for both calcium and sodium by atomic absorption spectroscopy. Because the ratio of calcium to sodium in the brine 18 known, determining the sodium in the floc allowed us to approximately correct the amount of calcium measured by subtracting out the amount present in the brine entrained by the floc. Washing the floc removed most of the calcium and sodium that had been present in the brine entrained in 1t. Because there was apparently no solid calclum carbonate present in the floc, we were unable to determine whether or not this washing procedure would have dissolved away part of it.

We belleve that these procedures are sensitive enough to detect less than $1 \mathrm{mg} \mathrm{L}^{-1}$ of solid calcium carbonate suspended in the "clarified brine," and less than $1 \%$ by dry weight of calcium carbonate in the floc. 
References

Allen, L, H. and E. Matljevil, "stabllity of Colloldal silica. I. Effect of Simple Electrolytes", J. Co11. Interface Sc1. 31, 287-296 (1969).

Allen, L. H. and E. MatijeviC, "Stability of Colloldal Sillca. II. Ion Exchange", J. Col1. Interface Sc1. 33, 420-429 (1970).

Allen, L. H. and E. Matifevie, "Stability of Colloidal Silica. III. Effect of Hydrolyzable Cations", J. Coll. Interface Sc1. 35, 66-75 (1971).

Alonso, H., B. Dominguez, M.J. LIppmann, R. Molinar, R.C. Schroeder, and P.A. Witherspoon, "Update on Reservior Engineering Activities at Cerro Prieto", presented at the Fifth Annual Stanford Geothermal Reservolr Engineering Workshop, held at Stanford University, December 12-14, 1979. (Proceedings in press.)

Barkman, J.H., and D.H. Davidson, "Measuring Water Quality and Predicting Well Impalrment", J. Petroleum Tech., pp.865-73 (1972).

Cosner, S.R., and J.A. Apps, "A Compllation of Data on Fluids from Geothermal Resources in the United States", Report LBL-5936, Lawrence Berkeley Laboratory, May 1978.

Hurtado, R., F. Gartbald1, R. Dfaz C., J.J. Fausto and S. Mercado, "Geothermal Brine Treatment for Reinjection at Cerro Prieto", presented at the Second Symposium on the Cerro Prieto Geothermal Field, Baja California, Mexico, held at Mexical1, October 17-19, 1979. (Proceedings in press.)

Iler, R. K.; "Colloldal Silica", pp. 1-100 in Surface and Collold Science, Vo1. 6, E. Mat1jeviC, ed., John W1ley \& Sons, Inc. (New York, 1973).

Iler, R. K., Lectures on sllica chemistry presented at the Lawrence Livermore Laboratory, October $14-15,1975 a$.

Iler, R. K., "Coagulation of Colloldal Sillca by Calcium Ions, Mechanism, and Effect of Colloid S1ze", J. Coll. Interface Sc1. 53, 476-488 (1975b).

Iler, R.K., The Chemistry of Silica: Solubllity, Polymerlzation, Collold and Surface Properties, and Biochemistry, John Wiley \& Sons (New York, 1979).

Lessor, D. L., 1979, personal communication.

Matijevil, E., "Colloid Stability and Complex Chemistry", J. Coll. Interface Sc1. $43,217-245$ (1973).

Pitzer, R.S., "Thermodynamics of Electrolytes. I. Theoretical Basis and General Equations", J. Phys. Chem. 17, 268-277(1973).

Quong, R., F. Schoepfiln, N. D. Stout, G. E. Tardiff and F. R. McLain (1978)

"Processing of Geothermal Brine Effluents for Injection", Geothermal Energy - Novelty Becomes Resource: Transactions lof the] Geothermal Resources Council Annual Meeting, Hilo, Hawa1i, 25-27 Juily, 1978, Vol. II, pp. 551-554. 
Rothbaum, H. P. and B. H. Anderton, "Removal of Sillca and Arsenic from Geothermal Discharge Waters by Precipitation of Useful Calcium Silicates", Proceedings [of the] Second Untted Nations Symposium on the Development and Use of Geothermal Resources, San Franc1sco, California, USA, May 20$29,1975, \mathrm{pp} \cdot 1417-1425$.

Weres, 0., L. Tsao and A. Yee, "Rinetics of Silica Polymerization." Report LBL-7033, Lawrence Berkeley Laboratory, Berkeley, CA. (In press, 1980). 